\title{
Trafficking Networks and the Mexican Drug War*
}

\author{
Melissa Dell \\ Harvard
}

August, 2014

\begin{abstract}
Drug trade-related violence has escalated dramatically in Mexico since 2007, and recent years have also witnessed large-scale efforts to combat trafficking, spearheaded by Mexico's conservative PAN party. This study examines the direct and spillover effects of Mexican policy towards the drug trade. Regression discontinuity estimates show that drug-related violence increases substantially after close elections of PAN mayors. Empirical evidence suggests that the violence reflects rival traffickers' attempts to usurp territories after crackdowns have weakened incumbent criminals. Moreover, the study uses a network model of trafficking routes to show that PAN victories divert drug traffic, increasing violence along alternative drug routes.
\end{abstract}

Keywords: Drug trafficking, networks, violence.

*I am grateful to Daron Acemoglu and Ben Olken for their extensive feedback on this project. I also thank Arturo Aguilar, Abhijit Banerjee, Ernesto Dal Bó, Dave Donaldson, Esther Duflo, Ray Fisman, Rachel Glennerster, Gordon Hanson, Austin Huang, Panle Jia, Chappell Lawson, Nick Ryan, Andreas Schulz, Jake Shapiro, and seminar participants at Bocconi University, the Brown University Networks conference, Chicago Booth, CIDE, Colegio de Mexico, Columbia, CU Boulder, George Mason, Harvard, the Inter-American Development Bank, ITAM, the Mexican Security in Comparative Perspective conference (Stanford), MIT, the NBER Political Economy Meeting, NEUDC, Princeton, Stanford, University of British Columbia, UC Berkeley Haas School of Business, UC San Diego, University of Chicago, University of Leicester, University of Maryland, US Customs and Border Patrol, the World Bank, and Yale for extremely helpful comments and suggestions. Contact email: melissadell@fas.harvard.edu, address: Harvard University Department of Economics, Littauer Center M-24, Cambridge MA 02138. 


\section{Introduction}

Drug trade-related violence has escalated dramatically in Mexico since 2007, claiming over 60,000 lives and raising concerns about the capacity of the state to monopolize violence. Recent years have also witnessed large scale efforts to combat drug trafficking, spearheaded by Mexico's conservative National Action Party (PAN). These efforts have cost around 9 billion USD per annum, nearly as much as the government expends on social development. ${ }^{1}$ Yet there is limited causal evidence about the impacts of crackdowns. This study uses plausibly exogenous variation from close Mexican mayoral elections, a network model of drug trafficking, and confidential data on the drug trade to identify how crackdowns have affected violence and trafficking. It examines both the direct effects of crackdowns in the places experiencing them and the spillover effects they exert by diverting drug traffic elsewhere.

Mexico is the largest supplier to the U.S. illicit drug market, with Mexican traffickers earning approximately 25 billion USD each year in wholesale U.S. drug markets (U.N. World Drug Report, 2011). Official data described later in this study document that in 2008, drug trafficking organizations maintained operations in two thirds of Mexico's municipalities, and illicit drugs were cultivated in $14 \%$ of municipalities.

While Mexico is a major player in the drug trade, its high levels of drug violence and drug enforcement expenditures are not unique. Global annual drug enforcement spending exceeds 100 billion USD, and traffickers in Central America, West Africa, and elsewhere use violent tactics and often belong to the same transnational trafficking organizations that operate in Mexico (Economics Briefing, 2013). Because law enforcement does not randomly decide where to crack down, the existing evidence on drug enforcement impacts consists primarily of correlations. While often the best evidence available, these can be non-trivial to interpret. For example, a positive cross-sectional correlation between violence and drug enforcement could result because areas with higher violence attribute it to drug consumption and thus expend more fighting the drug trade, and a positive correlation in a panel could occur because governments crack down in places where they expect violence to later increase.

This study isolates plausibly exogenous variation in drug enforcement policy by exploiting the outcomes of 2007-2010 close mayoral elections involving the PAN party. ${ }^{2}$ The PAN federal government's role in spearheading the war on drug trafficking, as well as qualitative evidence that PAN mayors have contributed to these efforts, motivate this empirical strategy. While municipalities where PAN candidates win and lose by wide margins are likely to be

\footnotetext{
${ }^{1}$ See Estados Unidos de Mexico, Gobierno Federal (2010) and Keefer and Loayza (2010). Social development encompasses a variety of anti-poverty programs, the most prominent of which is the extensively evaluated Progresa/Oportunidades conditional cash transfer program.

${ }^{2}$ See Lee, Moretti, and Butler (2004) for a pioneering example of a regression discontinuity design exploiting close elections. A number of studies have used discontinuous changes in policies, in the cross-section or over time, to examine illicit behavior. See Zitzewitz (2011) for a detailed review.
} 
different, when focusing on close elections it becomes plausible that election outcomes are driven by idiosyncratic factors. The study shows that the outcomes of close elections are in fact uncorrelated with baseline municipal characteristics and violence trends.

Regression discontinuity estimates document that there are 27 to 33 more drug traderelated homicides per 100,000 municipal inhabitants per annum after a PAN mayor takes office in a municipality than after a non-PAN mayor takes office, and these effects persist throughout the mayor's term and plausibly beyond. Relative to the pre-period, drug traderelated violence increases by a factor of 5.5 in municipalities with a close PAN victory, as compared to doubling in municipalities with a PAN loss. These results are robust to alternative specifications, samples, and lengths of the analysis period and to using the overall homicide rate, which is balanced throughout the 17 years of available pre-period data. Most of these homicides were not prosecuted, as just under $20 \%$ of homicides in Mexico result in an arrest (México Evalúa, 2012). Homicide is typically in the jurisdiction of Mexico's statelevel criminal justice systems, and in several of the most violent states the clearance rate for homicide is only three to seven percent. RD evidence also documents that police-criminal confrontations increase substantially following PAN inaugurations.

Over $90 \%$ of the violence consists of drug traffickers killing each other, and the increases in violence are concentrated in municipalities that are plausibly the most valuable for drug trafficking organizations to control. Analysis using information on the industrial organization of trafficking suggests that the violence reflects rival traffickers' attempts to wrest control of territories after crackdowns initiated by PAN mayors have weakened the incumbent traffickers. The violence does not appear to be explained by differences in corruption between the PAN and other parties or by several other alternative hypotheses that are explored.

These results provide novel evidence that crackdowns caused large and sustained increases in the homicide rate. They contribute to a literature - consisting primarily of cross-sectional and panel correlations across countries or cities/states, particularly within the US - which on balance documents a positive relationship between drug enforcement and violence. Miron (forthcoming), Werb et al. (2011), and Keefer and Loayza (2010) offer detailed reviews. ${ }^{3}$

The study's results also compliment qualitative and descriptive studies arguing that Mexican government policy has been the primary cause of the large spike in violence in recent years (Guerrero, 2011; Escalante, 2011; Merino, 2011), as well as recent work by Durante and Gutierrez (2014), who use close Mexican elections to argue that coordination across municipalities can reduce drug violence. ${ }^{4}$ The findings contrast with studies arguing that

\footnotetext{
${ }^{3}$ Examples of cross-country studies include Miron (2001) and Fajnzylber, Lederman, and Loayza (1998). Examples of studies within the U.S. include Brumm and Cloninger (1995); Miron (1999); and Rasmussen, Benson, and Sollars (1993).

${ }^{4}$ Guerrero compiles extensive qualitative and descriptive evidence suggesting that government policies have ignited violent conflicts between traffickers. Escalante documents a state level correlation between
} 
the increase in Mexican violence can primarily be explained by the diversification of drug trafficking organizations into new criminal activities, by increased arms availability, by increased U.S. deportation of immigrants with a criminal record, by job loss, or by cultural shifts in morality (see Williams, 2012; Escalante et al, 2011, Rios, 2011a for a discussion).

Finally, the results on mechanisms relate to work by Angrist and Kugler (2008) documenting that exogenous increases in coca prices spurred violence in rural districts in Colombia because combatant groups fought over the additional rents. In Mexico, crackdowns likely reduce rents from criminal activities while in effect, but by weakening the incumbent criminals they also reduce the costs of taking control of a municipality. Controlling territory plausibly offers substantial rents from trafficking and a variety of other criminal activities once the crackdown and its violent aftermath subside. While the study shows that the violent effects of crackdowns are sustained in the medium run, trafficking organizations may have a longer run horizon or might have underestimated how long gang wars would last.

When policy leads one location to become less conducive to illicit activity, organized crime may relocate elsewhere, affecting violence in other municipalities. ${ }^{5}$ Examining these spillovers is central to understanding the broader impacts of crackdowns. A number of studies have examined the drug trade and organized crime, but to the best of my knowledge this study is the first to empirically identify spillover patterns in drug trade activity. ${ }^{6}$ To do so, the study develops a network model of trafficking routes that predicts where drug traffic - and potentially drug violence - is diverted following crackdowns.

Traffickers' objective is to minimize the costs of transporting drugs from producing municipalities in Mexico across the road network to U.S. entry points. In the simplest version of the model, traffickers take the most direct route to the U.S. that avoids municipalities with a closely elected PAN mayor. PAN victories increase the costs of trafficking drugs through a municipality, diverting least cost routes elsewhere. Because elections occur at different times during the sample period, this generates plausibly exogenous within-municipality variation in predicted routes throughout Mexico. This variation from close elections is essential to identifying spillovers because it breaks the well-known reflection problem, allowing spillovers

homicides and the deployment of the Mexican military and federal police, and Merino expands Escalante's analysis by using a matching strategy to argue that Mexican homicides in 2008-2009 would have totaled 14,000 rather than 19,000 in the absence of intervention.

${ }^{5}$ For example, in a non drug-related context, work by Di Tella and Schargrodsky (2004) documents that the allocation of police officers to Jewish institutions in Buenos Aires substantially reduced auto theft in the immediate vicinity but may also have diverted some theft to as close as two blocks away.

${ }^{6}$ Studies of the economics of organized crime include Levitt and Venkatesh's analysis of the finances of a U.S. drug gang (2000); Gambetta's economic analysis of the Sicilian mafia (1996); Pinotti's (2012) study of the economic costs of organized crime in southern Italy; Bandiera (2003), Dimico et al. (2012) and Buonanno et al.'s (2012) investigations of the historical origins of the Sicilian mafia; Varese's (2005) and Frye and Zhuravskaya's (2000) analyses of the rise of the Russian mafia; and Mastrobuoni and Patacchini's (2010) study of the network structure of crime syndicates. 
to be isolated from correlations (Manski, 1993). Traffickers may care about the routes other traffickers take, and thus the study also estimates a richer model that imposes congestion costs when routes coincide. The approach is illustrated in Figure 1, and predicted routes for the beginning of the sample period are shown in Figure 2.

When a municipality acquires a predicted route, the monthly probability that a drug trade-related homicide occurs increases from a baseline probability of $4.8 \%$ to $6.2 \%$, and for each additional route the drug trade-related homicide rate increases by 0.54 per 100,000. There is some evidence that violence spillovers are concentrated in municipalities where multiple routes coincide. While the magnitudes of violence spillovers are typically small compared to the direct effects of crackdowns, they are nevertheless important given the gravity of homicides.

The study also examines how within-municipality variation in predicted routes compares to within-municipality variation in actual illicit drug seizures. This exercise can validate whether the trafficking model is predictive, as changes in drug confiscations are not used to estimate the routes. The value of drug seizures increases by $18 \%$ when a municipality acquires a predicted trafficking route, and this estimate is significant at the $1 \%$ level. Robustness and placebo checks also support the validity of the network approach.

In addition to validating the model, the drug seizures results can shed some light on the "diversion hypothesis", which argues that when the government cracks down in one place, drug activity is partially diverted elsewhere without being substantially reduced. The diversion hypothesis plays a major role in debates over the War on Drugs and is a leading explanation popularly given for why - despite a massive increase in drug enforcement expenditures globally over the past forty years - drug markets have continued to expand and drug use has not declined (UNODC, 2010; Reuter and Trautmann, 2009; ODCPP, 2002). For example, descriptive evidence suggests that coca eradication policies in Bolivia and Peru during the late 1990s led cultivation to shift to Colombia, and large-scale coca eradication in Colombia in the early 2000s has since led cultivation to re-expand in Peru and Bolivia, with total coca cultivation unchanged (Isacson, 2010; Leech, 2000; UN Office on Drugs and Crime 1999-2009). In the context of the Mexican Drug War, the shares of Mexican heroin and possibly other Mexican drugs in the U.S. market actually increased during the Calderón crackdown (Dìaz-Briseño, 2010). While the counterfactual is not clear - a problem that more generally plagues the predominantly descriptive and anecdotal evidence about the diversion hypothesis - this hypothesis is a potential explanation.

Estimating the share of drugs diverted and the share no longer trafficked through Mexico would require making potentially untenable assumptions about drug cultivation and seizure rates. Nevertheless, the study's results document that the diversion of drug traffic following crackdowns was large enough to substantially increase illicit drug seizures along predicted 
alternative routes. Combined with the fact that some law enforcement resources used for drug seizures and eradication were re-directed during the Calderón administration to focus on steeply increasing rates of violence (National Drug Intelligence Center, 2010), these results suggest that it is unlikely that the Mexican Drug War led to large, sustained reductions in the supply or consumption of illicit drugs.

While there are a variety of outcomes that could be affected by drug crackdowns, this study focuses on violence and the diversion of drug traffic since these are particularly central to policy and academic debates about the War on Drugs. It does briefly examines economic outcomes - finding negative impacts of crackdowns on informal sector earnings and female labor force participation. Formal sector wages and male labor force participation are not significantly affected. While the economic effects are noisily estimated, they are consistent with qualitative evidence that drug trafficking organizations not only set up smuggling operations but also extort informal sector producers via protection rackets.

This study's results document that the costs of the drug war, in terms of lives lost, have been high and sustained. Beyond the violence costs, there are also opportunity costs of the Mexican government expending approximately nine billion USD per annum fighting drug trafficking. While evidence is imperfect and the existence of countervailing benefits that outweigh these costs - such as impacts on drug consumption, corruption, or wages cannot be disproved, available evidence does not indicate that large positive impacts on these outcomes are particularly probable. The results of the study overall suggest policies aimed at deterring violence, enforcing homicide laws, and confronting other challenges, as opposed to policies whose primary objective is to reduce drug trafficking.

The next section provides an overview of Mexican drug trafficking. Section 3 then tests whether the outcomes of close elections affect violence in the municipalities experiencing these elections and examines the economic mechanisms underlying the results. Section 4 develops the network model of drug trafficking and tests whether PAN victories exert drug trafficking and violence spillovers. Finally, Section 5 concludes.

\section{Drugs and Violence in Mexico}

\subsection{The Drug Trafficking Industry}

Mexican drug traffickers dominate the wholesale illicit drug market in the United States, earning between 14 and 48 billion USD annually. ${ }^{7}$ According to the U.N. World Drug Report,

\footnotetext{
${ }^{7}$ Estimates are from the U.S. State Department (2009). Estimates by U.S. Immigration and Customs Enforcement, the U.S. Drug Enforcement Agency, and the Mexican Secretaría de Seguridad Pública are broadly similar and also contain a large margin of error.
} 
Mexico is the largest supplier of heroin to U.S. markets and the largest foreign supplier of marijuana and methamphetamine. Official Mexican government data, obtained from confidential sources, document that fourteen percent of Mexico's municipalities regularly produce opium poppy seed (heroin) or cannabis. Moreover, 60 to 90 percent of cocaine consumed in the U.S. transits through Mexico (U.S. Drug Enforcement Agency, 2011). The U.S. market provides substantially more revenue than Mexico's domestic drug market, which is worth an estimated 560 million USD annually (Secretaría de Seguridad Pública, 2010). ${ }^{8}$

At the beginning of this study's sample period, in December 2006, there were six major drug trafficking organizations (DTOs) in Mexico. Official data obtained from confidential sources document that 68 percent of Mexico's 2,456 municipalities were known to have a major DTO or local drug gang operating within their limits in early 2008. These data also estimate that 49 percent of drug producing municipalities were controlled by a major trafficking organization, with the remaining controlled by local gangs.

The term 'cartel', used colloquially to refer to DTOs, is a misnomer, as these organizations do not collude to reduce illicit drug production or to set prices. Alliances between DTOs are highly unstable, and there is considerable decentralization and conflict within DTOs (Williams, 2012; Guerrero, 2011, p. 10, 106-108). Decisions about day-to-day operations are typically made by local cells, as this ensures that no single trafficker will be able to reveal extensive information if captured by authorities. Moreover, the number of major DTOs increased from six in 2007 to 16 by 2011, with groups splitting over leadership disputes.

In addition to trafficking drugs, Mexican DTOs engage in a host of illicit activities that range from protection rackets, kidnapping, human smuggling, and prostitution to oil and fuel theft, money laundering, weapons trafficking, arson, and auto theft (Guerrero, 2011, p. 10). Notably, protection rackets involving the general population have increased substantially in recent years (Rios, 2011b; Secretariado Ejecutivo del Sistema Nacional de Seguridad Pública, 2011). The poor, who have limited recourse to state protection, are particularly likely to be extorted (Díaz-Cayeros et al., 2011).

The second half of the 2000s witnessed large, rapid increases in drug trade-related violence. Over 50,000 people were killed by drug trade-related violence between 2007 and 2012, and homicides increased by at least $30 \%$ per year during most of this period (Rios, 2011b). By 2010, violent civilian deaths per capita had reached levels higher than in Iraq and Afghanistan during the same period, higher than in Russia during the 1990s, and higher than in Sicily following the Second World War (Williams, 2012). Over 85 percent of the drug violence consisted of people involved in the drug trade killing each other, 95 percent of

\footnotetext{
${ }^{8}$ According to the U.S. National Survey on Drug Use and Health, 14.2 percent of Americans (35.5 million people) have used illicit drugs during the past year, as contrasted to 1.4 percent of the Mexican population (1.1 million people) (National Addiction Survey, 2008).
} 
the victims were male, and 45 percent were under age 30 . The violence has been public and brutal, with bodies hung from busy overpasses and severed heads placed in public spaces (Williams, 2012). Public displays of brutality and activities such as kidnapping and extortion affect the general public, and 2011 public opinion surveys found that security was more likely than the economy to be chosen as the largest problem facing the country.

\subsection{Mexico's War on Drug Trafficking}

Combating drug trafficking has been a major priority of the Mexican federal government in recent years. Notably, President Felipe Calderón (December 2006 - 2012) of the conservative National Action Party (PAN) made fighting organized crime the centerpiece of his administration. During his second week in office, Calderón deployed 6,500 federal troops to combat trafficking, and by the close of his presidency approximately 45,000 troops were involved.

For most of the 20th century, a single party, the PRI (Institutionalized Revolutionary Party), dominated Mexican politics. The PRI historically took a passive stance towards the drug trade, and widespread drug-related corruption is well-documented (Shannon, 1988; Chabat, 2010). Mexicans elected their first opposition president in 2000, and today Mexico has three major parties: the PAN on the right, the PRI, and the PRD (Party of the Democratic Revolution) on the left. While presidents Ernesto Zedillo (1994-2000, PRI) and Vicente Fox (2000-2006, PAN) did implement security reforms and crackdowns (Chabat, 2010), these were on a lesser scale than Calderón's. Calderón's crackdown appears to have been unanticipated, as the 2006 presidential election - decided by an extremely narrow margin - made limited mention of security issues (Aguilar and Castaneda, 2009).

Mexico's crackdown on trafficking has focused on arrests and enforcement against traffickers, whereas illicit crop eradication has declined somewhat as resources have been diverted to respond to violence (National Drug Intelligence Center, 2010). Drug seizures and high level arrests are typically made by the federal police and military, who have the requisite training and weaponry to fight heavily armed traffickers. Municipal police are relevant because they can provide local information for federal interventions, which often target specific actors about whom reliable information is available (Chabat, 2010). Municipal police also serve as valuable allies for traffickers, collecting information on who is passing through a town. This information is essential for protecting criminal operations and anticipating attacks by federal authorities and rivals. ${ }^{9}$ Municipal police form the largest group of public servants killed by drug-related violence (Guerrero, 2011).

Mayors name the municipal police chief and set policies regarding police conduct. Thus, PAN mayors could assist Calderón's drug war by appointing amenable law enforcement au-

\footnotetext{
${ }^{9}$ See for example El Pais, August 262010.
} 
thorities and by encouraging them to share information with the PAN federal government. Qualitative evidence indicates that PAN mayors under Calderón were more likely to request law enforcement assistance from the PAN federal government than their non-PAN counterparts and also suggests that operations involving the federal police and military have been most effective when local authorities are politically aligned with the federal government (Guerrero, 2011, p. 70). ${ }^{10}$

PAN mayors may have been more likely to aid Calderón's war on drugs because authorities from the same party cooperate more effectively, because of differences in corruption, or because of ideology. For example, Nathan Jones (2012) argues based on fieldwork conducted in Baja California that PAN politicians not only received more military assistance than their non-PAN counterparts but also were provided with newer, more sophisticated military hardware. Corruption will be discussed quantitatively later in this study. Moreover, PAN mayors plausibly had strong career incentives to cooperate. Mexican mayors are barred from consecutive reelection and securing a subsequent political post typically requires support from party leaders. ${ }^{11}$ For example, the mayorship is a common stepping stone to national politics, and a substantial part of the Mexican Congress is elected from closed party lists. ${ }^{12}$ PAN party leaders choose these lists, and if a candidate is placed high enough, she will enter the legislature (Langston, 2008; Wuhs, 2006). Parties likewise distribute millions of pesos in public campaign resources, and the federal government controls thousands of appointed posts (Langston, 2008).

The criminal justice system is also relevant for understanding the effects of crackdowns. Like the U.S., Mexico has state and federal criminal justice systems, and homicides are typically in the jurisdiction of the states. The clearance rate for homicides in Mexico is low, with just under $20 \%$ of homicides resulting in an arrest (México Evalúa, 2012), and the national average masks substantial regional variation. In the state of Chihuahua, only 3.6\% of homicides in 2010 resulted in an arrest by the end of the following year, with Durango and Sinaloa close behind at $4.6 \%$ and $7 \%$, respectively. In contrast, Yucatan had a clearance rate of $100 \%$ for the 34 homicides that it experienced in 2010 and Baja California Sur had a clearance rate of $90 \%$. States with the lowest clearance rates tend to be the most violent. For comparison, the clearance rate for homicides in the U.S. is around $67 \%$, ranging from

\footnotetext{
${ }^{10}$ For example, while drug trade-related violence initially increased in Baja California in response to a large federal intervention, the violence has since declined, and the state is frequently showcased as a federal intervention success story (Guerrero, 2011). The governor of Baja California belonged to the PAN, and the federal intervention began under the auspices of a PAN mayor in Tijuana. On the other hand, in Ciudad Juarez both the mayor and governor belonged to the opposing PRI party, and conflicts and mistrust between municipal and federal police have been rampant.

${ }^{11}$ The PAN controlled the mayorship in around a third of municipalities at the beginning of the sample.

${ }^{12}$ In a survey of 1,400 representatives who had served in Mexico's lower house of Congress, $77 \%$ of the PAN legislators had previously been involved in municipal politics (Langston, 2008). 200 of the 500 seats in the lower house of Congress and 32 of the 128 Senate seats are filled from the party lists.
} 
a low of $52 \%$ in Michigan to a high of $89 \%$ in Wyoming (FBI Uniform Crime Statistics, 2013). Low clearance rates in Mexico result from difficulties in both investigating homicides and apprehending suspects. Only $36 \%$ of warrants result in an arrest, with the arrest rate ranging from $14 \%$ to $76 \%$ across Mexican states (México Evalúa, 2012 and 2010). The federal government passed major judicial reforms in 2008, but the system remains weak.

These statistics, however, should not be interpreted as evidence that the Mexican federal government is incapable of arresting wanted criminals in a targeted manner. Drug-related crimes and organized criminal activity are often federal offenses, and nearly half of all federal inmates are charged with drug-related crimes (Zepeda, 2013; México Evalúa, 2013). Having the cooperation of local authorities can be central in making drug trade-related arrests, and confidential data on high level drug arrests shows that - while rare - they are about twice as common following close PAN victories as compared to close PAN losses.

These facts can plausibly help explain why violence has increased dramatically in Mexico in recent years. With the help of municipal authorities, the federal government has used a targeted strategy to arrest drug traffickers on federal drug-related or organized crime charges, plausibly destabilizing drug gangs. Rival gangs knew they could violently exploit this weakness without much risk of being prosecuted by state criminal justice systems for homicide, at least in Mexico's most violent states. This equilibrium has influenced some policymakers and scholars, such as Mark Kleinman (2011), to argue that the Mexican federal government should explicitly target its drug enforcement strategy towards the most violent traffickers, rather than targeting drug trafficking activity per se. The results of the current study plausibly support this position.

\section{Direct Effects of Close PAN Victories on Violence}

This section uses a regression discontinuity approach to test whether the outcomes of close mayoral elections affect violence in the municipalities experiencing these elections. It first describes the data and identification strategy. Then it examines the relationship between PAN victories and violence, as well as the economic mechanisms underlying this relationship.

\subsection{Data}

The analysis uses official government data on drug trade-related outcomes, obtained from confidential sources unless otherwise noted. Data on drug trade-related homicides occurring between December of 2006 and October of 2011 were compiled by a committee with representatives from all ministries that are members of the National Council of Public Security. ${ }^{13}$

\footnotetext{
${ }^{13}$ The Mexican government stopped compiling these data after October of 2011.
} 
This committee met each week to classify which homicides from the past week were drug trade-related. ${ }^{14}$ Drug trade-related homicides are defined as any instance in which a civilian kills another civilian, with at least one of the parties involved in the drug trade. The classification is made using information in the police reports and validated whenever possible using newspapers. The committee also maintains a database of those killed in armed clashes between police and organized criminals. Month x municipality data on all homicides occurring between 1990 and 2012 were obtained from the National Institute of Statistics and Geography (INEGI) and allow examination of a longer pre and post period than the drug trade-related homicide data. The overall homicide data are drawn from vital statistics compiled by state government authorities in each of Mexico's 31 states and federal district. Month x municipality confidential data on high level drug arrests are also employed. ${ }^{15}$

Moreover, this section uses official government data on which of Mexico's 2456 municipalities had a DTO or local drug gang operating within their limits in early 2008. This offers the closest available approximation to pre-period DTO presence, as systematic municipal-level data about DTOs were not collected before this time.

Finally, electoral data for elections occurring during 2007-2010 were obtained from the electoral authorities in each of Mexico's states. The sources for a number of other variables, used to examine whether the RD sample is balanced, are listed in the notes to Table 1.

\subsection{Econometric Framework}

This study uses a regression discontinuity (RD) approach to estimate the impact of PAN victories on violence. The RD strategy exploits the fact that the party affiliation of a municipality's mayor changes discontinuously at the threshold between a PAN victory and loss. Municipalities where the PAN wins by a large margin are likely to be different from municipalities where the PAN loses by a wide margin. However, when we narrow our focus to the set of municipalities with close elections, it becomes more plausible that election outcomes are determined by idiosyncratic factors and not by systematic municipal characteristics that could also affect violence. Thus, under certain conditions municipalities where the PAN barely lost can serve as a reasonable counterfactual for municipalities where they barely won. This section examines the plausibility of the RD identifying assumptions in detail, but first it is helpful to specify the regression form. The baseline analysis estimates the following regression model within a narrow window around the PAN win-loss threshold:

$$
y_{m}=\alpha_{0}+\alpha_{1} P A N \text { win }_{m}+\alpha_{2} P A N \text { win }_{m} \times f\left(\text { spread }_{m}\right)+\alpha_{3}\left(1-P A N \text { win }_{m}\right) \times f\left(\text { spread }_{m}\right)+\epsilon_{m}
$$

\footnotetext{
${ }^{14}$ Previous homicides are also considered for reclassification if new information becomes available.

${ }^{15}$ High level traffickers include DTO kingpins, regional lieutenants, assassins, and financiers.
} 
where $y_{m}$ is the outcome of interest in municipality $m$. PANwin $m$ is an indicator equal to 1 if the PAN candidate won the election, and spread $_{m}$ is the margin of PAN victory. The study examines robustness to different functional forms, $f(\cdot)$, for the RD polynomial, which is estimated separately on either side of the PAN win-loss threshold. Some robustness specifications also include region fixed effects and baseline controls.

Elections in Mexico occur at different times throughout the sample period. The study considers two samples: close elections occurring in 2007-2008 and close elections occurring in 2007-2010. The former provides a longer post-inauguration period but fewer municipalities. In order to be able to check for violence pre-trends, both samples are limited to municipalities with at least half a year of drug-trade related homicide data prior to the elections. The samples are also limited to municipalities with at least a year of post-inauguration data, so that violence effects can be examined in the medium-term.

Identification requires that all relevant factors besides treatment vary smoothly at the threshold between a PAN victory and loss. Formally, letting $y_{1}$ and $y_{0}$ denote potential outcomes under a PAN victory and loss, identification requires that $E\left[y_{1} \mid\right.$ spread $]$ and $E\left[y_{0} \mid\right.$ spread $]$ are continuous at the win-loss threshold. This assumption is needed for municipalities where the PAN barely lost to be an appropriate counterfactual for those where they barely won. This assumption would be violated if the outcomes of close elections were determined not by idiosyncratic factors but by a systematic advantage of winners. ${ }^{16}$

To assess the plausibility of the identifying assumptions, Table 1 examines whether 25 political, economic, demographic, road network, and geographic pre-characteristics are balanced across the PAN win-loss threshold. The next section considers violence trends prior to the relevant elections. The body of the study focuses on the baseline 2007-2008 elections sample for municipalities with a vote spread of five percentage points or less, and the appendix provides analogous results for the 2007-2010 elections and for alternative bandwidths. ${ }^{17}$

Column (1) reports the mean value of each characteristic in municipalities where the PAN won, column (2) does the same for municipalities where they lost, and column (3) reports the t-statistic on the difference. In no case are there statistically significant differences, including for political characteristics such as turnout and the party of the incumbent. ${ }^{18}$ I also estimate the RD specification given by equation (1) using each of the baseline characteristics as the dependent variable. The coefficients on PAN win are reported in column (4) and t-statistics in column (5). While some of the coefficients are noisily estimated, they are statistically identical to zero. Appendix Figures A-2 through A-5 show analogous RD plots for each characteristic. Regional characteristics could also differ across the PAN win-loss threshold,

\footnotetext{
${ }^{16}$ For example, Caughey and Sekhon (2011) show that in U.S. House elections between 1942 and 2008, close winners have financial and incumbency advantages.

${ }^{17}$ Figure A-1 shows a map of the close election municipalities, which are located throughout Mexico.

${ }^{18}$ The economically large difference in surface area is driven by a single large municipality, Ensenada.
} 
and thus I calculate the average of each baseline characteristic in the municipalities that border each municipality in the RD sample. Columns (6) and (7) repeat the RD analysis using these characteristics as the dependent variable. Again, while some coefficients are noisy, nearly all are statistically insignificant.

To provide a more complete view of how pre-characteristics vary around the threshold, Appendix Tables A-1 through A-4 repeat this analysis limiting the sample to vote spread bandwidths of 4\%,3\%,2\%, and 13.3\% (the Imbens-Kalyanaraman bandwidth), respectively, and Tables A-5 through A-9 do the same for the 2007-2010 close election sample. These tables document qualitatively similar patterns. ${ }^{19}$

When all pre-characteristics are combined into a single measure based on their ability to predict post-period violence - providing a higher powered test of whether pre-characteristics are balanced - there likewise is not a discontinuity at the PAN win-loss threshold. Specifically, I regress average violence during the post-period - which lasts for the duration of a mayor's term - on all the characteristics from Table 1, as well as on average violence during the pre-period. Both the average monthly probability that at least one homicide occurs and the average homicide rate are considered. I then use the coefficients from this regression to predict post-period violence, and Figure A-6 plots the predicted violence measures against the PAN margin of victory. Panel A examines the predicted drug-related homicide probability, Panel B the predicted drug-related homicide rate, Panel $\mathrm{C}$ the predicted overall homicide probability, and Panel $\mathrm{D}$ the predicted overall homicide rate. In no case is there a statistically significant discontinuity, and the magnitude of the discontinuity is modest.

Identification also requires the absence of selective sorting around the PAN win-loss threshold. This assumption would be violated, for example, if elections were rigged in favor of the PAN in municipalities that would later experience an increase in violence. To formally test for sorting, I implement McCrary's (2008) test by collapsing the election data to one percentage point vote spread bins and using the observation count in each bin as the dependent variable in equation (1). Appendix Figures A-7 and A-8 show that there is not a discontinuous change at the PAN win-loss threshold for either the 2007-2008 or 2007-2010 close election samples. In other words, neither the PAN nor its opponents systematically win close elections. For manipulation of the threshold to be consistent with these figures and Table 1, there would need to be an equal number of elections rigged in favor of and against the PAN, and the pre-characteristics would need to be the same on average for these municipalities and their neighbors, a scenario that is unlikely.

The absence of selective sorting is also institutionally plausible. Elections in Mexico

\footnotetext{
${ }^{19}$ Regressions using the Imbens-Kalyanaraman bandwidth use a triangular kernel such that the weight given to each observation decays with distance from the threshold. This is the standard approach for implementing the Imbens-Kalyanaraman bandwidth - which is estimated assuming that kernel weighting will be used. The other bandwidths produce very similar estimates when combined with kernel weighting.
} 
are coordinated by a multi-partisan state commission, and genuine recourse exists in the case of suspected fraud. While traffickers may have incentives to intimidate voters and candidates, recall that mayors prior to the Calderón administration had limited capacity to challenge heavily armed traffickers given the absence of a widespread federal crackdown. The elections, particularly for the 2007-2008 sample, are at the beginning of Calderón's crackdown, when traffickers were unlikely to have anticipated how sustained it would be and the role mayors would play. Thus, they may not have found it worthwhile to influence local elections. Consistent with this conjecture, systematic killings of mayors by traffickers began only after the federal crackdown had been sustained for several years.

\subsection{Graphical Analysis of Violence Patterns}

This section graphically analyzes the relationship between close election outcomes and violence, documenting that violence is similar prior to elections but diverges significantly thereafter. The main body of the paper focuses on the 2007-2008 close election sample, in which the post-inauguration period encompasses the mayor's three year term.

Figure 3 examines the probability that at least one drug trade-related homicide occurs in a given month and the homicide rate, both averaged across the pre-election, lame duck, and post-election periods. It plots the violence measures against the PAN margin of victory, with a negative margin indicating a PAN loss. Each point represents average violence in 0.5 percentage point vote spread bins. The solid line plots predicted values from a regression of violence on a quadratic polynomial in the vote spread, estimated separately on either side of the PAN win-loss threshold, and the dashed lines show 95\% confidence intervals.

While close PAN victories do not significantly increase the average probability that drug trade-related violence occurs during the mayor's subsequent term (Panel A), the drug-related homicide rate increases by around 40 per 100,000 following a close PAN victory, as compared to a close PAN loss (Panel B). At the threshold, violence is around three times higher in PAN municipalities. In contrast, Panel C (Panel D) shows that the drug trade-related homicide probability (rate) during the 2 to 5 month period following the election but prior to the inauguration of new authorities is similar regardless of whether the PAN barely won or lost. Finally, Panels E and F document the absence of a violence discontinuity at the PAN win-loss threshold during the six months prior to the elections, providing additional evidence that the RD sample is balanced. Appendix Figure A-9 presents an analogous figure for the 2007-2010 elections, documenting similar patterns. ${ }^{20}$ Violence is somewhat higher nearer the threshold, on both sides, in the pre as well as post-periods. ${ }^{21}$ This is plausibly explained by the fact

\footnotetext{
${ }^{20}$ Appendix Figure A-11 shows that both the 2007-2008 and 2007-2010 estimates are similar in magnitude when a negative binomial model is used to account for the count nature of the homicide rate.

${ }^{21}$ See Appendix Table A-46 for an examination of the relationship between the absolute value of the vote
} 
that drug trade-related violence is concentrated in larger, more urban municipalities, which are more likely to have very close elections (see Appendix Figure A-2).

Figure 4 provides an analogous exercise for overall homicides, in order to address two potential concerns with the drug trade-related homicide data. First, while homicides are classified as drug trade-related by a national committee, it is possible that the police reports used to make this classification systematically differ across municipalities. Moreover, the pre-period in the drug trade-related homicide data is relatively short since the data were not collected prior to President Calderón's inauguration in December of 2006. The overall homicide data are available for 1990-2012 and hence offer a much longer pre-period.

The patterns documented in Figure 4 are similar to those in Figure 3. There is a significant increase in the overall homicide rate following the inauguration of PAN mayors (Panel B), whereas violence during the pre-period - which in this case extends over 17 years - is balanced. ${ }^{22}$ Appendix Figure A-10 documents analogous overall homicide patterns in the 2007-2010 close election sample. ${ }^{23}$ Since it is quite unlikely that homicide differences of this magnitude would be driven by differences in reporting, these results provide strong evidence that there is a genuine increase in violence following PAN victories. The overall homicide estimates tend to be somewhat larger in magnitude than the drug trade-related homicide estimates, and the positive correlation between changes from month-to-month in drug-related homicides and overall homicides net drug-related homicides suggests that some homicides related to drug gang wars may not have been classified as such.

To uncover more detail about the relationship between violence and PAN victories, I estimate equation (1) separately for each quarter prior to the election and following the inauguration of new authorities. Figure 5 plots the PAN win coefficients against time, which is defined relative to each municipality's election and inauguration. The thin lines plot 95\% confidence intervals, and the thick lines plot $90 \%$ confidence intervals. Quarterly data are used to improve the legibility of the plots, and similar patterns are documented using monthly data in Appendix Figure A-13.

Panel A documents that the probability that at least one drug-related homicide occurs in a given month increases for one to two quarters following the mayor's inauguration, but the difference between PAN and non-PAN municipalities converges back to zero after this. ${ }^{24}$ In contrast, the drug trade-related homicide rate increases in the first quarter following the inauguration of a new PAN mayor and remains higher than in non-PAN municipalities

\footnotetext{
spread and violence.

${ }^{22}$ Results (available upon request) are also similar when overall homicides are considered using the same period as for the drug trade-related homicides.

${ }^{23}$ Figure A-12 documents similar results for the homicide rate using a negative binomial model.

${ }^{24}$ Whether the impact is statistically significant in the second quarter varies with the specification used, though coefficient magnitudes are similar across specifications.
} 
throughout the remainder of the mayor's term. Drug violence in the pre-election period is balanced for both the extensive margin and homicide rate. Likewise, Panel $\mathrm{C}$ shows that the overall homicide rate is balanced throughout the seventeen years prior to the relevant elections. The homicide rate increases following the inaugurations of PAN mayors and remains significantly higher in PAN municipalities for as long as data are available. The violence differences do not subside when new mayors take office in 2010 and 2011. ${ }^{25}$ Appendix Figures A-15-A-23 show that these results are robust to using different bandwidths $(4 \%, 3 \%, 2 \%$, and $13.3 \%$, the Imbens-Kalyanaraman bandwidth) and controls, and Appendix Figure A-24 documents that violence is also balanced in neighboring municipalities prior to the elections.

\subsection{Further Results and Robustness}

Tables 2 and 3 estimate the RD specification given in equation (1) - using either a linear or quadratic RD polynomial - for the 2007-2008 and 2007-2010 close election samples. ${ }^{26}$ The coefficients on PAN win in the specification using the quadratic RD polynomial estimate the discontinuities in Figures 3 and 4, and the linear polynomial provides a robustness check. Panel A considers drug trade-related homicides and Panel B overall homicides.

Table 2 documents that close PAN victories increase the drug trade-related homicide rate by between 33 (s.e. $=9$ ) and 42 (s.e. $=8$ ) homicides per 100,000 per annum during the mayor's three year term. Table 3 considers close elections occurring between 2007 and 2010, estimating that PAN victories increases the drug-related homicide rate by 18 (s.e.=6) to 27 $($ s.e. $=9)$ homicides per 100,000 during the one year following the mayor's inauguration. The difference between these estimates is explained by the post-period lengths. When the analysis examining 2007-2008 elections uses a one year post-inauguration period, the estimated impact of close PAN victories is 22 per 100,000. The estimates for the overall homicide rate show a similar pattern but are somewhat larger in magnitude, as discussed above. Columns (1) through (6) of both tables document that close PAN victories do not have a sustained impact on the violence extensive margin.

Back of the envelope calculations suggest that crackdowns are responsible for at least half of the increase in homicides in Mexico in recent years. When using 2007-2008 elections to compare the drug trade-related homicide rate in the pre and post periods, the homicide rate approximately doubles in municipalities where the PAN barely loses and increases by a factor of 5.5 in places where the PAN barely wins. Similarly, the overall homicide rate in municipalities with close PAN elections in 2007-2008 nearly doubles in municipalities with

\footnotetext{
${ }^{25}$ The probability of at least one homicide occurring in a given month is also balanced across the full 17 year period prior to the elections, see Figure A-14.

${ }^{26}$ The homicide rate is more noisily measured in smaller municipalities. Thus, following the standard approach in the crime literature, regressions use inverse variance weighting.
} 
a PAN loss and increases by a factor of four in municipalities with a PAN victory. These estimates are likely a lower bound since the party of the mayor is not the sole determinant of federal security assistance.

The appendix conducts a number of additional robustness checks. First, Appendix Tables A-10 and A-11 examine the robustness of the drug trade-related homicide rate estimates to using alternative bandwidths $(5 \%, 4 \%, 3 \%, 2 \%$, and $13.3 \%$ - the Imbens-Kalyanaraman bandwidth), alternative RD polynomials (linear, quadratic, cubic, and quartic, estimated separately on either side of the PAN win-loss threshold), and alternative inclusions of controls, for the 2007-2008 and 2007-2010 samples respectively. Appendix Tables A-12 and A-13 perform an analogous exercise for the overall homicide rate. The coefficients reported in the main text fall towards the middle of the distribution of the 132 coefficients reported in each of the analogous robustness tables and tend to be statistically similar. Moreover, Appendix Figures A-25 and A-26 document that PAN victories robustly increase the homicide rate, regardless of the length of the analysis period. ${ }^{27}$ I focus on close elections because they allow for causal identification. For completeness, Table A-14 reports that when all PAN elections are included in the sample, effects on violence are positive but only statistically significant for the overall homicide rate.

If violence before the elections is balanced, a differences-in-differences specification will estimate PAN win effects that are similar to the RD coefficients. Appendix Tables A-15-A-24 - which each explore a different vote spread bandwidth (5\%,4\%,3\%,2\%, and 13.3\%) and dependent variable (the drug trade-related or overall homicide rate) - document that this approach does indeed produce estimates similar to those from the RD, for both the 20072008 and 2007-2010 close election samples. This remains true even when the differences-indifferences specifications control for municipality-specific time trends.

\subsection{Interpretation}

This section examines the mechanisms through which PAN victories affect drug trade-related violence, over $85 \%$ of which consists of traffickers killing each other. The evidence suggests that PAN victories lead to crackdowns that weaken incumbent criminals, spurring violence between traffickers.

First, consider whether PAN victories lead to crackdowns. Municipality level data on military and federal police deployments cannot be released to individuals outside these organi-

\footnotetext{
${ }^{27}$ Figure A-25 shows that results using the drug trade-related homicide rate are robust to varying the pre-period from one to six months, the lame duck period from one to five months, and the post-period from two to thirty-five months. Figure A-26 shows analogously that results for the overall homicide rate are robust to varying the pre-period from one to 205 months $(\approx 17$ years $)$, the lame duck period from one to five months, and the post-period from two to over 50 months.
} 
zations, but other available evidence suggests that PAN mayors are more likely to crack down on the drug trade. Appendix Table A-25 examines police-criminal confrontation causalities. Using the RD specification in equation (1), it documents that casualties are significantly higher in PAN than in non-PAN municipalities, for both the 2007-2008 and 2007-2010 election samples. In contrast, casualties are balanced in the pre-period. Arrests of high level drug traffickers, while rare, likewise occur more frequently following PAN victories. ${ }^{28}$

Table 4 examines whether the patterns of heterogeneity in the data are consistent with the hypothesis that crackdowns spur conflicts between traffickers. Columns (1) and (5) reproduce the baseline post-inauguration results for the 2007-2008 and 2007-2010 close election samples, respectively. Columns (2) and (6) examine whether effects are larger in municipalities that are closer to the U.S., where most illicit drugs are consumed. These municipalities are plausibly more valuable for traffickers to control and potentially more worth fighting over. I interact PAN win, spread, and PAN win $\times$ spread with an indicator equal to one if the municipality is greater than median distance from the U.S. In both the 2007-2008 and 20072010 close election samples, the effect of PAN victories on the post-inauguration homicide rate is large and positive in municipalities closer to the U.S. and smaller and statistically insignificant in municipalities further from the U.S. Appendix Tables A-26 - A-34 document robustness across different bandwidths and measures of the homicide rate (drug trade-related and overall homicides).

Columns (3) and (7) perform a similar exercise, interacting the PAN win indicator and RD polynomial with an indicator equal to 1 if the municipality had a below average homicide rate prior to Calderón's presidency. It is plausible that municipalities more valuable to the drug trade were already experiencing baseline violent conflict prior to the Mexican Drug War, and the extensive and intensive margin results in Tables 2 and 3 suggest that the sustained violence effects are concentrated in places that would have experienced some violence in any case. The heterogeneity results in Table 4 document that sustained increases in violence during the post-inauguration period are in fact concentrated in municipalities with an above average pre-period homicide rate. Results are similar regardless of the bandwidth or homicide measure used (Tables A-26 - A-34).

Crackdowns could plausibly ignite conflicts within DTOs if members fight to be promoted to the positions of higher level traffickers who have been arrested or killed. Crackdowns could also weaken the incumbent DTO, creating incentives for rival DTOs to violently wrest control of a territory while the incumbent is vulnerable. Incentives to usurp territory are plausibly greatest when the territory is nearby, as controlling an entire region allows traffickers to

\footnotetext{
${ }^{28}$ The federal government does not maintain a database of all drug-related arrests. During the postinauguration period, high level arrests happened twice as often in places where the PAN barely won.
} 
monopolize the many criminal activities in which they engage. ${ }^{29}$ To shed light on these hypotheses, I categorize municipalities into four groups using confidential data on DTOs: 1) municipalities controlled by a major DTO that border territory controlled by a rival 2) municipalities controlled by a major DTO that do not border territory controlled by a rival DTO 3) municipalities controlled by a local drug gang, and 4) no known drug trade presence. $^{30}$ Municipalities with no known drug trade presence had not experienced drug trade-related homicides or illicit drug confiscations at the time the DTO data were compiled, and local authorities had not reported the presence of a drug trade-related group.

Columns (4) and (8) of Table 4 interact these indicators with the RD terms, providing robust evidence that violence effects are concentrated where the control of territory is fragmented. PAN win effects are large, positive, and statistically significant in municipalities with a major DTO that border territory controlled by a rival, and Tables A-26 - A-34 show that these effects are highly robust across RD samples. There is also some evidence that PAN victories increase the homicide rate in municipalities controlled by a major DTO that border territory controlled by allies, although estimates are not statistically significant across all samples. With the $5 \%$ bandwidth, which is used in the main text, impacts are not statistically significant, but the coefficients are broadly similar to those estimated using the bandwidths examined in the appendix, which do tend to be statistically significant. These estimates suggest that PAN victories increase the drug-related homicide rate by between 5 and 16 per 100,000 in municipalities that border an ally, as compared to effects of around 35 per 100,000 in municipalities that border a rival. The effects for municipalities with a local drug gang and with no known drug trade presence are small and statistically insignificant.

Why would a rival DTO want to wrest control of territory experiencing a crackdown, as crackdowns and their violent aftermath could make the territory less profitable? Crackdowns are unlikely to persist in the long-run, and their violent aftermath plausibly also fades eventually. While the study finds that the violent effects of crackdowns are sustained in the medium-term, DTOs are multi-billion dollar businesses and may make long-run investment decisions that are expected to pay out only over a longer period than has elapsed since the start of the Mexican Drug War. Moreover, the level of drug violence in Mexico in recent years, as well as the widespread recruitment of ex-military special forces personnel by drug gangs, is unprecedented (Guerrero, 2011). Given recent changes in the weaponry and military strategies used to wage gang wars, DTOs may have underestimated the time and costs required to monopolize a territory after the incumbent DTO was weakened.

While this evidence suggests that crackdowns spur violence between traffickers, there are

\footnotetext{
${ }^{29}$ For example, a DTO can charge higher prices for prostitution if it controls brothels throughout a region than if it has to compete with a rival group.

${ }^{30}$ The major DTOs during the sample period are Beltran, Familia Michoacana, Golfo, Juarez, Sinaloa, Tijuana, and Zetas.
} 
other potential explanations of the PAN win effects that will be considered in turn. First, a PAN victory is more likely to signal a change in the party controlling the mayorship, which could spur violence by disrupting the status quo. The PAN is the incumbent party in around $30 \%$ of the 2007-2008 election sample and $37 \%$ of the 2007-2010 election sample, whereas the PRI is the incumbent party in around half of municipalities. This hypothesis is examined in Table 5. The dependent variable is the drug trade-related homicide rate in the post-inauguration period, with columns (1) through (6) examining the 2007-2008 close election sample and columns (7) through (12) the 2007-2010 close election sample.

Columns (1) and (7) report the baseline RD estimates, whereas columns (2) and (8) distinguish whether the PAN was the incumbent party. This specification includes the same terms as the baseline and also interacts PAN win, spread, and PAN win $\times$ spread with the incumbency dummy. Column (2) estimates that in municipalities with a non-PAN incumbent, close PAN victories increase the drug homicide rate during the mayor's subsequent term by 30 homicides per 100,000 (s.e. $=8$ ), whereas the estimated impact in municipalities with a PAN mayor previously is $-3($ s.e. $=5) .{ }^{31}$ For the 2007-2010 elections, the impact of PAN victories in municipalities without a PAN incumbent is 33 (s.e. $=10$ ), whereas the impact in municipalities with a PAN incumbent is 0.5 (s.e. $=4)$. Appendix Tables A-35 - A-43 document that these patterns are robust to bandwidth selection and to different homicide measures (drug trade-related and overall homicides).

Columns (3) and (9) interact the RD terms with an indicator equal to one if the party controlling the mayorship changed. ${ }^{32}$ The impact of an alternation on violence is smaller and statistically insignificant. While violence increases when the party switches to the PAN, it does not increase when the party switches to the PRI or PRD, so the average effect of an alternation is small.

As a further check, I examine close elections between the PRI and PRD. If alternations between parties spur violence, we would expect to see an impact of alternations in the PRIPRD sample, whereas if the violence effects are driven by the PAN, alternations should not influence violence in this sample. Results are consistent with the latter scenario. For comparison purposes, columns (4) and (10) run the standard RD specification comparing municipalities where the PRI or PRD barely won or lost, and the PRI win coefficient is positive but not statistically significant. Columns (5) and (11) examine whether alternations in this sample affect violence. The violence effects are small, equaling 4.4 (s.e. $=4.1)$ and -3.9 (s.e. $=7.2$ ) in columns $(5)$ and $(11)$, respectively. These results are robust across the samples and homicide measures examined in Appendix Tables A-35 - A-43.

\footnotetext{
${ }^{31}$ The coefficient in column (1) (column (7)) is not a simple weighted average of the coefficients in column (2) (column $(8))$ because the latter estimates the RD polynomial separately for municipalities with a PAN and non-PAN incumbent.

${ }^{32}$ Vote spread is negative when the party stays the same and positive when it changes.
} 
Governors control the deployment of state police and disbursement of state funds. Another alternative explanation is that security assistance from PAN governors - and not the PAN federal government - drives the results. This explanation is unlikely since less than 10\% of the sample is in a state with a PAN governor, and columns (6) and (12) of Table 5 show that the impact of PAN victories on violence is similar regardless of the governor's party. ${ }^{33}$

Beyond security assistance, PAN mayors could also in theory receive more economic assistance from the PAN federal government, which traffickers might fight to siphon off through extortion. While 90 percent of Mexican state and local spending are financed by federal transfers, economic resources are allocated transparently using formulas (Haggard and Webb, 2006). Since the RD sample is balanced on the characteristics used in these formulas, economic transfers do not differ between PAN and non-PAN municipalities. ${ }^{34}$

A final alternative hypothesis is that the violence effects result from differences in corruption between PAN and non-PAN mayors. While this hypothesis cannot be completely ruled out due to difficulties in observing corruption, the available evidence more strongly suggests that violence effects are driven by PAN mayors receiving federal security assistance. Official government data on mayoral corruption in 2008 offer unique insight into corruption at the local level, documenting around $25 \%$ of mayors in the RD sample engaging in corruption. The data are available for mayors who had taken office by 2008, providing 102 observations for the $5 \%$ vote spread bandwidth. Table A-44 examines the relationship between PAN victories and an indicator equal to 1 if the mayor was corrupt, with Panel A reporting a simple means comparison and Panel B including a linear RD polynomial. Estimates for five different bandwidths are reported. The coefficient on PAN win is typically small, relative to high mean levels of corruption, although the estimates become noisier once the vote spread trends are included. The most precise estimates use the 13.3\% (Imbens-Kalyanaraman) bandwidth, and equal 0.007 (s.e. $=0.055$ ) and -0.005 (s.e.=0.091) for the means comparison and RD.

Elections involving the PRI and PRD can provide an additional test of this hypothesis, and also suggest that corruption differences are unlikely to generate the violence results. The outcomes of PRI-PRD elections should matter for violence if the corruption hypothesis is true and there are significant differences in these parties' propensities to engage in corruption. The corruption data suggest that the PRI is more corrupt than the PRD, but columns (4) and (10) of Table 5 document that if anything violence is higher in places that barely elect

\footnotetext{
${ }^{33}$ Because few states have a PAN governor, caution must be used in interpreting these results when narrow bandwidths are used in the appendix.

${ }^{34}$ Municipalities receive federal resources through two main funds: the Fondo para la Infraestructura Social Municipal, which is distributed proportionally to the number of households living in extreme poverty, and the Fondo de Aportaciones para el Fortalecimiento de los Municipios, which is distributed proportionally to population. Resource transfers from state to local governments are less transparent, but recall that I do not find differences by the party of the state governor.
} 
a PRI mayor, although the differences are not statistically significant. ${ }^{35}$

\section{A Network Analysis of Spillover Effects}

Thus far the analysis has focused on how crackdowns in a given municipality affect that location, but crackdowns may also impact other municipalities by motivating traffickers to relocate their operations. This section utilizes a network model of drug trafficking to provide insight into where spillovers are likely to occur. It first specifies the baseline model and uses data on drug confiscations to test whether the model predicts the diversion of drug traffic following close PAN victories. It then examines whether close PAN victories increase violence along alternative trafficking routes and finally develops several extensions of the model.

\subsection{A Network Model of Drug Trafficking}

In order to test whether crackdowns affect violence and drug trafficking elsewhere, it is necessary to specify a model of where spillovers are likely to occur. DTOs are profit-maximizing entities who face economic constraints, and the trafficking model captures this in a simple and transparent way. In the model, traffickers minimize the costs of transporting drugs from producing municipalities in Mexico across the road network to U.S. points of entry. They incur costs from the physical distance traversed and from crackdowns and thus take the most direct route to the U.S. that avoids municipalities with crackdowns. This framework provides a starting point for examining patterns in the data without having to first develop extensive theoretical or empirical machinery. Section 4.3 will specify and estimate richer versions of the model that include congestion and other costs.

The model setup is as follows: let $N=(\mathcal{V}, \mathcal{E})$ be an undirected graph representing the Mexican road network, which consists of sets $\mathcal{V}$ of vertices and $\mathcal{E}$ of edges. Traffickers transport drugs across the network from a set of origins to a set of destinations. The routes are calculated using Dijkstra's algorithm (Dijkstra, 1959), an application of Bellman's principal of optimality. The appendix provides a formal statement of the problem.

Destinations consist of Mexico - U.S. border crossings and major Mexican ports. While drugs may also enter the United States between terrestrial border crossings, the large amount of legitimate commerce between Mexico and the United States offers ample opportunities for drug traffickers to smuggle large quantities of drugs through border crossings and ports

\footnotetext{
${ }^{35} \mathrm{RD}$ estimates of the impact of PRI victories on corruption (available upon request) are positive and statistically significant regardless of the bandwidth used. When using the five standard bandwidths employed throughout this study, two of the five means comparison estimates are statistically significant.
} 
(U.S. Drug Enforcement Agency, 2011). ${ }^{36}$ All destinations pay the same international price for a unit of smuggled drugs.

Each origin $i$ produces drugs and has a trafficker whose objective is to minimize the cost of trafficking these drugs to U.S. entry points. Producing municipalities are identified from confidential Mexican government data on drug cultivation (heroin and marijuana) and major drug labs (methamphetamine). In practice we know little about the quantity of drugs cultivated, and hence I make the simplifying assumption that each origin produces a single unit of drugs. Opium poppy seed and marijuana have a long history of production in specific regions with particularly suitable conditions, and thus the origins for domestically produced drugs are relatively stable throughout the sample period. In contrast, cocaine - which can only be produced in the Andean region - typically enters Mexico along the Pacific coast via small vessels at locations that are flexible and less well-known (U.S. Drug Enforcement Agency, 2011). Thus, I focus on trafficking routes for domestically produced drugs.

In the baseline spillovers analysis, I assume that close PAN victories increase the costs of trafficking drugs through a municipality to infinity when the PAN mayor takes office. Because mayors take office at different times throughout the sample period, close elections generate plausibly exogenous within-municipality variation in predicted routes across Mexico. If the aim of the exercise were purely predictive, routes in the baseline specification could also vary with landslide elections and other time varying characteristics. However, such an approach would not identify spillovers, due to the well-known reflection problem (Manski, 1993). For example, support for the PAN and drug trafficking activity could be growing in tandem in a region because of economic factors, generating correlations between politics in one municipality and violence nearby. In contrast, Table 1 and Figure A-24 show that the outcomes of close elections are uncorrelated with neighbors' characteristics and pre-period violence trends. For completeness, Section 4.3 nevertheless examines robustness to imposing costs to pass through all PAN municipalities.

There is a large and growing literature examining conflict and crime on networks. These studies tend to emphasize local bilateral interactions. For example, Ballester et al. (2006, 2010) model bilateral interactions between criminals on a network, identifying which player(s) should be arrested in order to reduce crime the most, and Konig et al. (2014) apply a similar key player analysis of bilateral interactions to insurgent groups in the Congo War. Baccara and Bar-Isaac (2008) use network tools to model how the information flow within criminal organizations might change in response to law enforcement strategies that target specific parts of the network, and Kovenock and Roberson (2012) employ a network to model the

\footnotetext{
${ }^{36}$ There are 370 million entries into the U.S. through terrestrial border crossings each year, and 116 million vehicles cross the land borders with Canada and Mexico (U.S. Drug Enforcement Agency, 2011). Each year more than 90,000 merchant and passenger ships dock at U.S. ports, and these ships carry more than 9 million shipping containers. Commerce between the U.S. and Mexico exceeds a billion dollars a day.
} 
relationships between conflicts on multiple battlefields. Brown, Carlyle, Salmeron and Wood (2005) examine how networks can be made less vulnerable to attack by terrorists, and Goyal and Vigier (2010) develop a related model where a designer chooses a network and an attacker chooses an attack strategy. Allocating defense budgets to a node of the network can prevent the attack from spreading locally to other nodes.

Core to the trafficking model is a global optimization decision - choosing a path across a congested network - whereas the networks literature in economics has focused largely on local bilateral interactions, for example between a farmer and his agricultural contacts or between criminal associates in the mafia. It would be appropriate to apply such a model to the trafficking problem if traffickers sold drugs to their associates in the next municipality over based on what was locally optimal, and these associates in turn sold the drugs to their locally optimal associates and so forth until the drugs were sold to a consumer in the United States. Instead, a single trafficker makes a global decision about how to transport drugs across a network, which is the problem that the routing model was designed to solve.

\subsection{Baseline Results}

To shed light on whether this simple model provides reasonable predictions of where spillovers are likely to occur, this section examines the relationship between model predicted routes and actual illicit drug confiscations using the following empirical specification:

$$
\operatorname{conf}_{m s t}=\beta_{0}+\beta_{1} \text { Routes }_{m s t}+\psi_{s t}+\delta_{m}+\epsilon_{m s t}
$$

where conf $f_{m s t}$ is confiscations of domestically produced drugs (marijuana, heroin, and methamphetamine) in municipality $m$, state $s$, month $t$. Official government data on confiscations of different types of drugs were obtained from confidential sources. Both an indicator and a continuous measure are examined. Routes $s_{m s}$ is a measure of predicted trafficking routes, $\psi_{s t}$ is a month $\mathrm{x}$ state fixed effect, and $\delta_{m}$ is a municipality fixed effect. The error term is clustered simultaneously by municipality and state-month to address spatial correlation (Cameron, Gelbach, and Miller, 2011), and the sample excludes municipalities that themselves experience a close election. ${ }^{37}$ The main text focuses on the 2007-2008 close election sample, and the baseline sample period extends through 2009, when mayors from all the 2007-2008 elections have taken office. To examine robustness to extending the length of the sample period, the appendix predicts trafficking routes using close elections between 2007 and 2010. The empirical approach is summarized in Figure 1.

\footnotetext{
${ }^{37}$ It also excludes producing municipalities, since much of the analysis focuses on the extensive margin of trafficking routes and producing municipalities mechanically contain a predicted trafficking route. Results (available upon request) are robust to including these municipalities.
} 
The municipality fixed effect ensures that $\beta_{1}$ is identified from within municipality variation. Thus, if enforcement is constant within municipalities over time, confiscations will provide a proxy for actual drug traffic. Typically, local politics does not change when a municipality acquires a predicted route, and thus relatively constant enforcement appears plausible. This assumption will be further examined in the empirical analysis.

Panel A of Table 6 reports estimates from equation (2). In column (1), the dependent variable is an indicator equal to one if domestically produced drugs (marijuana, heroin, or methamphetamine) were confiscated in the municipality-month and the routes measure is an indicator equal to one if the municipality had at least one predicted route in that month. When a municipality acquires a predicted route, the probability of confiscating drugs during a given month increases from a baseline of $5.4 \%$ to $7 \%$, and the effect is significant at the $1 \%$ level. In column (2), the dependent variable equals the log value (in US dollars) of drug seizures if they are positive and equals zero otherwise. This measure is always non-negative, as even the smallest confiscations are worth hundreds of dollars. ${ }^{38}$ Acquiring a predicted trafficking route is associated with an $18 \%$ increase in the total value of confiscated domestic drugs, and again the correlation is significant at the $1 \%$ level. Finally, column (3) uses a count measure of predicted routes, estimating that each predicted route increases the value of illicit drug confiscations by slightly over 2\%. Appendix Table A-47 examines robustness to using the 2007-2010 election sample and period. Results are broadly similar, although the relationship between confiscation value and the predicted routes dummy is no longer statistically significant.

These results suggest that the model can predict the diversion of drug traffic following PAN victories. However, if alternative routes traverse nearby municipalities and if the military or federal police become active throughout a region when deployed to PAN municipalities, this could generate a correlation between changes in predicted routes and confiscations that is unrelated to the diversion of drug traffic. In contrast, it is difficult to tell a plausible story in which PAN victories directly affect confiscations along alternative routes located further away. Columns (4)-(6) examine whether the model is predictive when I exclude municipalities bordering those with close PAN victories. The estimated coefficients are similar to those in columns (1)-(3) and remain statistically significant. ${ }^{39}$

Another concern is that authorities along alternative routes may have increased enforcement efforts in response to a small increase in drug traffic. In this case the model would

\footnotetext{
${ }^{38}$ Working in logs is attractive because drug confiscations are highly right-skewed, with several drug busts confiscating tens of millions of dollars of drugs.

${ }^{39}$ This contrasts to the 2007-2010 results, which are not significant for the limited sample. The limited sample offers little power for the 2007-2010 exercise since many more municipalities border a 2007-2010 close election municipality than border a 2007-2008 close election municipality. Moreover, some of the extensions in the following section will improve the fit for this sample.
} 
correctly identify the locations of spillovers, which is its central aim, but the confiscations data would exaggerate the magnitudes. To assess this possibility, I examine whether predicted domestic drug routes are correlated with cocaine confiscations. While cocaine and domestic routes ultimately intersect before reaching the U.S., in general they are different since cocaine entry points and drug producing municipalities are in distinct locations. When domestic drug traffic changes in a town that also contains a cocaine route, its cocaine route often will be unaffected by the change in local politics that diverted domestic drug traffic. Thus, if enforcement is constant, cocaine confiscations will on average change little when a municipality acquires or loses a domestic route. In contrast, if changes in enforcement drive most of the large increases in domestic drug confiscations that occur when a municipality acquires a predicted route, cocaine confiscations should also increase. Columns (7) through (9) document that within-municipality variation in predicted domestic routes is in fact uncorrelated with variation in the presence and value of cocaine confiscations. ${ }^{40}$

As a final check on the model, I show that the strong correlation between predicted routes and actual confiscations that Table 6 documents is unlikely to have arisen by chance. I randomly assign placebo close PAN victories such that the number of randomly selected municipalities that are infinitely costly to traverse increases each month by the number of close PAN inaugurations that actually occurred that month. I calculate predicted routes and regress confiscations on an indicator for the presence of a predicted route (along with municipality and state $\mathrm{x}$ month fixed effects), repeating this exercise 1000 times and plotting the coefficients in Appendix Figure A-27. Only six of the coefficients are statistically different from zero at the $5 \%$ level, and the coefficient from column (2) of Table 6 is in the far right tail of the coefficient distribution, more than three standard deviations above the mean.

Modeling the diversion of drug trafficking activity can shed some light on the "diversion hypothesis", which argues that when the government cracks down in one place, drug activity is partially diverted elsewhere without being substantially reduced. The diversion hypothesis plays a major role in debates over the War on Drugs and is a leading explanation popularly given for why - despite a massive increase in drug enforcement expenditure globally over the past forty years - drug markets have continued to expand and drug use has not declined (UNODC, 2010; Reuter and Trautmann, 2009; ODCPP, 2002). In the context of the Mexican Drug War, the shares of Mexican heroin and possibly other Mexican drugs in the U.S. market increased during the Calderón crackdown (Dìaz-Briseño, 2010). In this case, as with the other mostly qualitative and anecdotal evidence about the diversion hypothesis, the correlations are consistent with the diversion hypothesis but it is difficult to know the counterfactual.

\footnotetext{
${ }^{40}$ Results are similar when I limit the sample to municipalities with cocaine confiscations during the beginning of the sample period. Because of the municipality fixed effects, municipalities without cocaine confiscations only affect the routes coefficient through their influence on the fixed effects estimation.
} 
The current study addresses this concern by providing causal evidence about the diversion of drug traffic. While it would ideally quantify what percentage of drugs are diverted by crackdowns, what percentage continue to be trafficked along the original routes, and what percentage are no longer grown in Mexico, this would require making potentially untenable assumptions about drug cultivation and seizure rates. I am not aware of data that could be used to calculate how seizure rates vary across space before and after crackdowns - they plausibly change in the midst of a crackdown, which is why the study does not examine the direct effects of crackdowns on confiscations - nor are there data that quantify how many drugs were initially trafficked along each route. Nevertheless, the diversion of drug traffic following PAN victories is substantial enough to increase the value of illicit drug seizures by around $18 \%$ along each predicted alternative route. Combined with the fact that law enforcement resources used for drug seizures and eradication were ultimately re-directed during the Calderón administration to focus on steeply increasing rates of violence (National Drug Intelligence Center, 2010), these results suggest that it is unlikely that the Mexican Drug War led to large sustained reductions in the supply or consumption of illicit drugs.

Given that the trafficking model predicts the diversion of drug traffic following crackdowns, it can be used as an empirical tool to assess whether crackdowns affect violence by diverting illicit activity elsewhere. Specifically, Table 7 employs the panel specification from equation (2) to test whether homicides change when a municipality acquires a predicted trafficking route. Panel A, column (1) estimates that the presence of a predicted route increases the monthly drug trade-related homicide probability from a baseline of $4.8 \%$ to $6.2 \%$, and the effect is statistically significant at the $1 \%$ level. Column (2) does not find a statistically significantly relationship between the homicide rate and the predicted routes indicator, although the coefficient is positive, whereas column (3) uses the count measure of predicted routes and finds that each predicted route increases the homicide rate by 0.54 per 100,000 $($ s.e. $=0.3)$. Columns (4) and (5) distinguish whether the municipality contains none, one, or more than one predicted route. The coefficients on the one and more than one route indicators are positive and statistically identical for the homicide probability in column (4), but when examining the homicide rate in column (5), violence increases are concentrated in municipalities with more than one route. ${ }^{41}$ The coefficient on the more than one route indicator is large and statistically significant at the $5 \%$ level. This is consistent with the view that crackdowns spur conflicts between traffickers by diverting drug traffic to routes that are already in use.

Next, columns (6) through (10) examine the limited sample that excludes municipalities bordering a close PAN victory. While the effects are no longer statistically significant, the

\footnotetext{
${ }^{41}$ Results for both confiscations and violence are similar when I control for having a PAN mayor (Tables A-49 and A-50.
} 
routes coefficients in the full and limited samples are not statistically different. The extensions developed in the next section will improve the predictive power of the limited sample. Finally, Table A-48 documents broadly similar results for the 2007-2010 close election sample, particularly for the homicide rate measure. ${ }^{42}$

The straightforward model of drug trafficking offers additional traction over a reduced form approach. Tables A-51 and A-52 document that the trafficking model outperforms a reduced form model that counts a municipality as treated if it borders a municipality that has inaugurated a closely elected PAN mayor during the sample period. Neither confiscations nor violence is statistically significantly correlated with the reduced form treatment, and the coefficients are smaller than when the trafficking model is used to predict drug traffic.

While the violence spillovers are relatively small in magnitude, even a modest increase in a city's homicide rate due to other municipalities' crackdowns is likely to be of relevance due to the seriousness of the offense. The overall effects of spillovers are relatively small because the violence impacts of acquiring an additional trafficking route are substantially less than the direct effects of crackdowns, and the number of municipalities who acquire an additional route as a result of crackdowns - net of those who lose a route - is also modest. Back of the envelope calculations suggest that the direct effects of crackdowns are about 30 times larger than the spillover effects, though this is plausibly a lower bound since the network model is an imperfect predictor of where spillovers occur.

\subsection{Extensions}

This section develops several extensions of the spillovers analysis. First, it introduces more realism into the model by incorporating congestion costs and costs for transporting drugs through rival DTOs' territories. It also estimates the cost and duration of PAN crackdowns and examines additional outcomes. Finally, while the main objective of the trafficking model is to locate the spillover effects of crackdowns, the model has more general applications to problems where understanding the economics of trafficking is important. One particularly interesting application, to the allocation of law enforcement resources, is briefly developed.

\subsubsection{Congestion Costs}

This section introduces more realism into the shortest paths model by incorporating congestion costs when trafficking routes coincide. There are several reasons why edge latencies may depend on drug flows: as drug traffic increases, the probability of conflict with other traffickers may change; the quality of hiding places may decline, particularly at U.S. entry points; and law enforcement may direct more or less attention per unit of traffic.

\footnotetext{
${ }^{42}$ Impacts on the homicide probability are not statistically significant.
} 
The setup for the model with congestion costs is as follows: as in the shortest paths model, every origin produces a unit of drugs and has a trafficker who decides how to transport those drugs to U.S. entry points, which have a size given by the number of commercial lanes for terrestrial border crossings and the container capacity for ports. All U.S. entry points pay the same international price for a unit of drugs. Each edge $e$ has a cost function $c_{e}\left(l_{e}, x_{e}\right)$, where $l_{e}$ is the length of the edge and $x_{e}$ is the total drug flow on edge $e$. A trafficker's objective is to minimize the costs of transporting his municipality's drugs, taking aggregate flows as given. Recall that most trafficking decisions are made within local cells, so the assumption that traffickers are small is reasonable and simplifies the analysis. This assumption is relaxed later as a robustness check.

In equilibrium, the costs of all routes used to transport drugs from a producing municipality to the U.S. are equal and less than the cost that would be experienced by reallocating traffic to an unused route. These conditions were first formalized by John Wardrop (1952) and characterize the Nash equilibrium of the game. Formally, an equilibrium satisfies:

1. For all $p, p^{\prime} \in \mathcal{P}_{i}$ with $x_{p}, x_{p^{\prime}}>0, \sum_{e \in p^{\prime}} c_{e}\left(x_{e}, l_{e}\right)=\sum_{e \in p} c_{e}\left(x_{e}, l_{e}\right)$.

2. For all $p, p^{\prime} \in \mathcal{P}_{i}$ with $x_{p}>0 x_{p^{\prime}}=0, \sum_{e \in p^{\prime}} c_{e}\left(x_{e}, l_{e}\right) \geq \sum_{e \in p} c_{e}\left(x_{e}, l_{e}\right)$.

where $\mathcal{P}_{i}$ denotes the set of all possible paths between producing municipality $i$ and U.S. entry points and $x_{p}$ denotes the flow on path $p$. An equilibrium routing pattern always exists, and if each $c_{e}$ is strictly increasing, it is unique. The equilibrium is not typically socially optimal, since traffickers do not internalize the congestion externalities. Note that the shortest paths model is a special case of the more general model where congestion costs are assumed to be zero.

Beckmann, McGuire, and Winsten (1956) proved that the equilibrium can be characterized by a straightforward optimization problem, which is stated in the estimation appendix. For a given network, set of supplies, and specification of the congestion $\operatorname{costs} c_{e}(\cdot)$, the problem can be solved using numerical methods, also detailed in the appendix.

Edge costs in this more general model are not directly observed. To make progress, the study assumes that congestion costs take a Cobb-Douglas form. In the most parsimonious specification, traffickers incur costs to enter the U.S. that depend on the amount of drug traffic using the entry point, normalized by the entry point's size. Formally, edges connecting Mexico to the U.S. (which by definition are of length zero) impose costs equal to $\phi_{t}\left(\text { flow }_{e} / \text { lanes }\right)^{\delta}$ for terrestrial border crossings and $\phi_{p}\left(\text { flow }_{e} / \text { container } s\right)^{\delta}$ for ports, where $\left\{\phi_{t}, \phi_{p}, \delta\right\}$ are parameters that will be estimated, lanes is the number of commercial crossing lanes, and containers is the port container capacity. $\delta$ captures the shape of congestion costs, and $\left\{\phi_{t}, \phi_{p}\right\}$ scale these costs to the same units as physical distance. Interior edges are not congested: $c_{e}^{i n t}\left(l_{e}, x_{e}\right)=l_{e}$. The appendix also estimates a more flexible specification 
with six $\phi$ parameters for different sizes of terrestrial crossings and ports, as well as a specification with congestion costs on crossing and interior edges: $c_{e}^{i n t}=l_{e}\left(1+\phi_{\text {int }}\right.$ flow $\left.l_{e}^{\gamma}\right)$, where $\phi_{\text {int }}$ and $\gamma$ are parameters whose interpretations are analogous to $\phi_{t} / \phi_{p}$ and $\delta .{ }^{43}$ Congestion costs, particularly in the most flexible models, should be interpreted broadly. For example, if traffickers prefer large crossings because they are closer to U.S. population centers, this will appear as lower estimated congestion costs for large crossings.

The above parameters, as well as a scaling parameter $\kappa$ that maps model-predicted flows to model-predicted confiscations, are estimated using the simulated method of moments (SMM). ${ }^{44}$ Every choice of the model's parameters generates a set of moments that summarize model-predicted confiscations, and the study estimates the parameters by matching these moments to their counterparts calculated from cross-sectional data on actual illicit drug confiscations during the beginning of the sample period. ${ }^{45}$ The estimation appendix specifies the SMM objective, lists the moments, and discusses inference. ${ }^{46}$

Appendix Table A-53 reports the parameter estimates. ${ }^{47}$ All three specifications estimate convex congestion costs on U.S. entry points $(\delta>1)$, and interior congestion appears modest, with total congestion costs at U.S. entry points 39 times larger than total interior congestion costs. This appears plausible, as U.S. entry points are bottlenecks with a large law enforcement presence. All specifications estimate that total congestion costs are nearly as large as total distance costs. Predicted pre-period routes are shown in Figure 2

As expected given the SMM approach, model predicted and actual pre-period confiscations are highly correlated. The more challenging test is whether the model, fitted using pre-period data, can predict changes in confiscations during later periods. I examine this by using the panel specification given in equation (2) to compare within-municipality variation in predicted routes and actual confiscations. The routes are calculated using the three congestion parameters in column (1) of Table A-53, and Appendix Tables A-54 and A-55 document robustness to using alternative parameterizations of congestion.

Panel B of Table 6 shows that the estimates using the congestion model are similar to those using the shortest path model. Columns (1) through (3) estimate that when a municipality acquires a predicted route, the probability of confiscations increases by 1.3 percentage points $($ s.e. $=0.005)$, and the value of confiscations increases by around $15 \%$ (s.e.=

\footnotetext{
${ }^{43}$ Results are robust to specifying interior $\operatorname{costs}$ as $l_{e}+\phi_{\text {int }}$ flow . $_{e}$.

${ }^{44} \kappa$ likely varies with the local environment, but it is not possible to estimate this dependence.

${ }^{45}$ This lasts from December 2006, when the data become available, until the first authorities elected during the sample period took office in July 2007.

${ }^{46} \mathrm{As}$ is often the case with choice problems, the SMM objective is not globally convex. Thus I minimize the objective using simulated annealing. It is not possible to guarantee that an estimation procedure will find the global minimum of a non-convex objective, but Monte Carlo type simulations suggest that the trafficking problem is well-behaved.

${ }^{47}$ Conley standard errors are in brackets, and robust standard errors are in parentheses.
} 
0.057). There is not a statistically significant relationship between the count of predicted routes and the value of confiscations. Columns (4) through (6) document robustness to excluding municipalities bordering a municipality that has experienced a close PAN victory, and columns (7) through (9) show that the correlations between predicted domestic routes and the presence/value of cocaine confiscations are low. Results are also robust to assuming that traffickers are non-atomic. ${ }^{48}$ The similarity between the shortest paths and congestion results is consistent with a world in which the risk of confiscations by authorities and other criminals increases with time on the road, and hence traffickers prefer to use direct routes.

The shortest path and congested routing models also estimate similar violence spillovers. Panel B of Table 7 reports that the probability of drug trade-related violence increases by 1.7 percentage points $($ s.e. $=0.005)$ when a municipality acquires a predicted route, and the homicide rate increases by around 2 per 100,000 (s.e.=0.8). Columns (6) through (10) document that estimates are similar in the limited sample, which drops municipalities that border a close PAN victory. ${ }^{49}$

Thus far, the model has not imposed costs for transporting drugs through territory controlled by a rival DTO. For several reasons, I focus on this as a robustness check and not as the main specification. With ideal data, one could estimate these costs by matching predicted routes for each DTO to confiscations made from that DTO. However, DTO x municipality confiscations data are not available. Additionally, $51 \%$ of producing municipalities are controlled by local gangs, and there is not information on which larger organizations, if any, these groups coordinate with to transport drugs. Finally, DTO costs impose playerspecific edge latencies, and a trafficking equilibrium may not exist (Gairing, Monien, and Tiemann, 2011). In any case, least cost routes between producing municipalities controlled by a major DTO and U.S. entry points tend to pass primarily through territory controlled by that DTO, so territorial costs may not influence the trafficking equilibrium much.

In the territorial costs robustness check, decisionmakers - consisting of a single representative for each DTO and drug producing gang - minimize the costs of transporting their group's drugs to the U.S. Costs are incurred from passing through another DTO's territory, as well as from distance or distance and congestion. ${ }^{50}$ Table A-56 shows that the coefficients from regressing actual confiscations or drug-related homicides on the predicted routes

\footnotetext{
${ }^{48}$ When I assume that non-atomic DTOs and local gangs make trafficking decisions, with a single decisionmaker for each DTO, predicted routes are still statistically significantly correlated with actual confiscations, but these predicted routes lose a horse race to the atomic decisionmaker predicted routes. This is consistent with the qualitative evidence that most decisions within DTOs are decentralized.

${ }^{49}$ The violence results are weaker for the 2007-2010 sample (Table A-48), but the next section will show that they become stronger when the cost and duration of PAN crackdowns are estimated.

${ }^{50} \mathrm{To}$ solve the routing game for a given set of parameters, the best response functions are iterated to convergence. Although an equilibrium is not guaranteed to exist, simulations show that the best responses always converge to a unique equilibrium regardless of the starting point. Parameters are estimated using SMM, and the moments are listed in the appendix.
} 
dummy are positive and often - though not always - significant, regardless of whether congestion costs are estimated or assumed to be zero. When I regress actual confiscations on both the routes dummy from this model and the routes dummy from the model without territorial costs, only the coefficient on the latter is large and statistically significant (regardless of whether congestion costs are included), suggesting that territorial costs are noisily inferred from available data.

\subsubsection{Estimating the costs and duration of PAN crackdowns}

The baseline model assumes that crackdowns impose infinite costs on trafficking drugs through a municipality and persist through the end of the sample period. In order to examine robustness to these assumptions, I use the simulated method of moments to estimate the cost and duration of PAN crackdowns. Specifically, I match confiscations to predicted routes using data from all available periods, choosing the crackdown cost and duration parameters such that the evolution of confiscations matches the evolution of predicted trafficking routes as closely as possible. Unlike in the baseline model - where the congestion parameters are estimated using a single cross-section - the PAN cost and duration parameters are identified from changes in confiscation patterns when the PAN takes office. I cannot validate the richer model by comparing changes in predicted routes to changes in confiscations because they match by construction, and for this reason I examine this model as a robustness check and not as a main specification. The estimates of the violence spillovers of crackdowns are similar to the baseline model, as the PAN cost parameter is sufficiently high that most drug traffic circumvents PAN municipalities, and the crackdown duration parameter is not binding for most municipalities. Since the direct effects of PAN crackdowns on violence also persist for as long as data are available, the direct and spillover results appear quite consistent.

If the effects of PAN victories on trafficking are similar regardless of the margin of victory, the model's predictions could plausibly be improved by imposing a cost to pass through all municipalities with a PAN mayor. Using the approach outlined above, I estimate the cost and duration of PAN victories using the close elections and then plug these parameters in for all municipalities that elect a PAN mayor, regardless of the margin of victory. Estimates using routes predicted by the richer model are presented in Appendix Table A-57. Estimates are similar to the baseline model when 2007-2008 elections are used, whereas the fit improves substantially when 2007-2010 elections are examined.

\subsubsection{Additional outcomes}

In order to assess the full effects of the Mexican Drug War, one would ideally examine an extensive range of outcomes, including drug consumption, drug prices, and economic 
variables. Much of these data are not available at a sufficiently disaggregated level, but labor force data can be used to shed light on the economic effects of crackdowns. The National Occupation and Employment Survey surveys municipalities on a quarterly basis. While it does not offer enough coverage of the RD sample to elucidate the direct economic effects of crackdowns, the sample is larger when considering spillovers. ${ }^{51}$

While the results are noisy, there is little compelling evidence for positive average wage impacts that would be substantial enough to outweigh the costs of the Mexican Drug War. Appendix Table A-58 shows that - when the congested routing model is used - the presence of a predicted trafficking route lowers female labor force participation by 1.3 percentage points $($ s.e. $=0.57)$, relative to an average female participation rate of 51 percent, but does not affect male labor force participation. It also documents that predicted routes are uncorrelated with prime-aged male formal sector wages, whereas informal sector earnings fall by around 2.3 percent (s.e. $=1.3$ ) when a municipality acquires a predicted route. ${ }^{52}$ When the shortest path routes are used, estimates are statistically identical to the estimates using the congested routes but are not statistically different from zero. Informal sector workers - and women more generally - are often self-employed, and the survey calculates their earnings as monthly profits divided by hours worked. If informal sector workers report their earnings as net of rents extracted by traffickers, then extortion by drug gangs - which appears to be widespread - could explain the decline (Díaz-Cayeros et al., 2011).

\subsubsection{Endogenizing crackdowns}

The routing model's insights into the economics of trafficking can be applied to other important questions faced by law enforcement and national security officials. While the study's focus is on evaluating the impacts of crackdowns, this section provides an illustrative example of how the routing model can be applied to a different question: how to make crackdowns more efficient, conditional on pursuing them. This question is highly relevant in the current policy environment, but it is treated as a secondary result since the study's empirical estimates raise questions about the desirability of cracking down in the first place.

The setup for this application is as follows. The trafficking model is embedded in a Stackelberg network game (Baş and Srikant, 2002), with the government deciding in the first stage how to allocate law enforcement resources to edges in the road network, subject to a budget constraint. Traffickers' costs of traversing an edge increase when law enforcement resources are placed on it. In the second stage, traffickers simultaneously select least cost routes to the U.S. The government's objective is to maximize the total costs that traffickers incur, and

\footnotetext{
${ }^{51}$ Moreover, it is possible that PAN mayors might influence economic outcomes in their municipalities through channels besides security policy.

${ }^{52}$ Formal sector workers are those that contribute to the federal social security system.
} 
each trafficker minimizes his own costs. This framework can accommodate multiple types of resources with deployment costs that vary by edge. The most closely related work methodologically is a study by Israeli and Wood (2002), which develops an efficient algorithm to solve for which $\mathrm{k}$ edges to remove in the context of a non-congested shortest path problem on a directed graph with a single origin and destination. This study's problem examines an enriched setting with congestion and multiple origins and destinations. ${ }^{53}$

There are several things to note about how the network structure conditions the equilibrium allocation of law enforcement resources. First, while a naive policy might allocate law enforcement to edges with the most drug traffic, the network model highlights that the extent to which law enforcement affects trafficking costs depends on available detours. In fact, increasing an edge's latency can decrease total trafficking costs if there are externalities from congestion. This result, known as Braess's paradox (1968), occurs for $15 \%$ of the edges in the congested trafficking equilibrium. Moreover, the effects of law enforcement in different locations are interconnected through the network structure, implying that resource allocation decisions should be made jointly rather than on a location-by-location basis.

The online appendix provides an illustrative example of how this framework can be used to inform the allocation of scarce law enforcement resources. It first shows that the government's allocation problem is NP hard, which implies that the time required to solve for the optimum increases quickly as the size of the problem grows. Intuitively, the problem is challenging because allocating resources to two edges at the same time might increase the government's objective function more than the summation of changes in the objective when resources are allocated to each edge separately. Hence the order in which a solution algorithm proceeds may matter. The estimation appendix develops an algorithm for solving the game, and Appendix Table A-59 documents robustness to changing the algorithm's details.

If the government has enough resources to triple the latencies on 25 edges (this is the factor by which PAN victories are estimated to increase edge costs), this will increase traffickers' total predicted costs by 17\%. This exercise illustrates how the network model can contribute unique information to interdiction efforts, as the 25 edges chosen differ from the 25 most trafficked edges.

This exercise is a simplified illustrative example, but with appropriate data it would be straightforward to extend the model to make it more realistic. Multiple types of law enforcement resources could be incorporated, as well as deployment costs that vary by edge. Future work could also examine mixed strategies by law enforcement, which may be desirable but are beyond the scope of the current study.

\footnotetext{
${ }^{53}$ While there are other studies that focus on removing key nodes or edges from a network - notably Ballester et al. $(2006,2010)$ - since the network interactions modeled by these studies are different the techniques for solving them are likewise quite distinct.
} 


\section{Conclusion}

This study examines the direct and spillover effects of Mexican crackdowns on the drug trade, documenting the following results. First, regression discontinuity estimates show that violence in a municipality increases substantially after the close election of a PAN mayor and remains higher throughout the mayor's term and beyond. The empirical evidence suggests that the violence largely reflects rival traffickers' attempts to wrest control of territories after crackdowns initiated by PAN mayors have challenged the incumbent criminals. Moreover, an economic model of equilibrium trafficking routes predicts the diversion of drug traffic following close PAN victories. This diversion is large enough to make a substantial difference in illicit drug seizures along alternative routes, and when drug traffic is diverted to other municipalities, violence in these municipalities increases.

These results demonstrate how traffickers' economic objectives and constraints imposed by the routes network have conditioned the policy outcomes of the Mexican Drug War. While further research is needed to identify the causal effects of crackdowns on additional outcomes and in alternative contexts, overall the study's results suggest policies aimed at deterring violence, enforcing homicide laws, and confronting other challenges, as opposed to policies whose primary objective is to reduce drug trafficking. 


\section{References}

Angrist, J. AND A. Kugler (2008): "Rural windfall or a new resource curse? Coca, income, and civil conflict in Colombia," The Review of Economics and Statistics, 90, 191215.

Beckmann, M., C. McGuire, and C. Winston (1956): Studies in the Economics of Transportation, Yale University Press.

Braess, D. (1968): "Über ein Paradoxon aus der Verkehrsplanung," Mathematical Methods of Operations Research, 12, 258-268.

Brumm, H. J. And D. O. Cloninger (1995): "Violent crime and punishment: an application of the LISREL model 1," Applied Economics, 27, 719-725.

Cameron, A. C., J. B. Gelbach, And D. L. Miller (2011): "Robust inference with multiway clustering," Journal of Business 65 Economic Statistics, 29.

Díaz-Cayeros, A., B. Magaloni, A. Matanock, And V. Romero (2011): "Living in Fear: Mapping the Social Embeddedness of Drug Gangs and Violence in Mexico," Manuscript: University of California at San Diego.

DiJKstRA, E. (1959): "A note on two problems in connection with graphs," Numerische mathematik, 1, 269-271.

Eaton, G., C. Davies, L. English, A. Lodwick, M. A. Bellis, and J. McVeigh (2007): United Kingdom drug situation: annual report to the European Monitoring Centre for Drugs and Drug Addiction $200 \%$.

Estados Unidos de Mexico, Gobierno Federal (2010): Oportunidades: A Program of Results.

FAjnzylber, P., D. Lederman, And N. LoAyza (1998): Determinants of crime rates in Latin America and the world: an empirical assessment, vol. 1 of World Bank Latin American and Caribbean studies, World Bank Publications.

Gambetta, D. (1993): The Sicilian Mafia, Harvard University Press.

Guerrero-Gutiérrez, E. (2011): "Security, Drugs, and Violence in Mexico: A Survey," 7th North American Forum, Washington D.C.

Imbens, G. And K. Kalyanaraman (2012): "Optimal bandwidth choice for the regression discontinuity estimator," The Review of Economic Studies, 79, 933-959.

Isacson, A. (2010): "Colombia: Don't Call it a Model," Policy Document: Washington Office on Latin America.

KeEFER, P. AND N. LOAYZA (2010): Innocent bystanders: developing countries and the war on drugs, World Bank Publications. 
Lee, D., E. Moretti, AND M. Butler (2004): "Do voters affect or elect policies? Evidence from the US House," The Quarterly Journal of Economics, 119, 807-859.

LeEch, G. (2000): "The Failure of Coca Eradication in Peru and Bolivia," Colombia Journal.

Levitt, S. And S. Venkatesh (2000): “An Economic Analysis of a Drug-Selling Gang's Finances," The Quarterly Journal of Economics, 115, 755-789.

MAnski, C. (1993): "Identification of endogenous social effects: The reflection problem," The Review of Economic Studies, 60, 531-542.

MÉxico Evalúa (2010): Índice de desempeño del sistema penal.

(2012): Seguridad y Justicia Penal en los Estados: 25 Indicadores de Nuestra debilidad institucional.

- (2013): La Cárcel en México: Para qué.

Miron, J. A. (1999): "Violence and the U.S. Prohibitions of Drugs and Alcohol," American Law and Economics Review, Fall, 78-114.

(2001a): "The Economics of Drug Prohibition and Drug Legalization," Social Research, 3, 835-855.

(2001b): "Violence, Guns, and Drugs: A Cross-Country Analysis," Journal of Law and Economics, 2, 615-634.

- (2010): "The Budgetary Implications of Drug Prohibition," 1-39.

_ (Forthcoming): "Drugs and Violence," Report for World Bank Project on Crime and Violence in Central America.

Rasmussen, D. W., B. L. Benson, and D. L. Sollars (1993): "Spatial competition in illicit drug markets: The consequences of increased drug law enforcement," The Review of Regional Studies, 23, 219-236.

Reuter, P. And F. Trautmann (2009): A Report on Global Illicit Drug Markets 1998$200 \%$.

Rios, V. (2011): "Understanding Mexico's Drug War," Manuscript: Harvard University Department of Government.

(2013): "Why did Mexico become so violent? A self-reinforcing violent equilibrium caused by competition and enforcement," Trends in Organized Crime, 16.

Secretaría De Salud, CONADIC (2008): National Addictions Survey.

Secretaría de Seguridad Pública (2010): Informe del Estado de la Seguridad Pública en México. 
Shannon, E. (1988): Desperados: Latin drug lords, US lawmen, and the war America can't win, Viking.

ShIRK, D. A. (2012): "Drug Violence and State Responses in Mexico," Manuscript: University of San Diego Department of Political Science.

The White House Office of National Drug Control Policy (2010): National Drug Control Strategy.

United Nations International Drug Control Programme and United Nations Office on Drugs and United Nations Office for Drug Control and Crime Prevention (2011): World Drug Report, United Nations Publications.

United Nations Office for Drug Control and Crime Prevention (2002): Studies on Drugs and Crime: Global Illicit Drug Trends 2002, United Nations Publications.

United Nations Office on Drugs and Crime (2010): World Drug Report 2010. (2011): World Drug Report 2011.

United States Drug Enforcement Agency (2011): Drug Trafficking in the United States.

VARESE, F. (2005): The Russian Mafia: private protection in a new market economy, Oxford University Press.

Wardrop, J. (1952): "Some Theoretical Aspects of Road Traffic Research," Proceedings of the Institution of Civil Engineers, 1, 325-378.

Werb, D., G. Rowell, G. Guyatt, T. Kerr, J. Montaner, and E. Wood (2011): "Effect of drug law enforcement on drug market violence: A systematic review," International Journal of Drug Policy, 22, 87-94.

Zepeda Lecuona, G. (2013): Situación y desafíos del sistema penitenciario mexicano.

Zitzewitz, E. (2012): "Forensic economics," Journal of Economic Literature, 50, 731-769. 


\section{Table 1: Baseline Characteristics}

\begin{tabular}{|c|c|c|c|c|c|c|c|}
\hline & $(1)$ & $(2)$ & $(3)$ & $(4)$ & $(5)$ & $(6)$ & $(7)$ \\
\hline & \multicolumn{5}{|c|}{ Own municipality } & \multicolumn{2}{|c|}{ Neighboring muns. } \\
\hline & $\begin{array}{l}5 \% \text { vot } \\
\text { PAN } \\
\text { won }\end{array}$ & $\begin{array}{c}\text { spread } \\
\text { PAN } \\
\text { lost }\end{array}$ & $\begin{array}{l}\text { t-stat on } \\
\text { means } \\
\text { difference }\end{array}$ & $\begin{array}{c}\mathrm{RD} \\
\text { estimate }\end{array}$ & $\begin{array}{l}\text { t-stat on } \\
\text { RD } \\
\text { estimate }\end{array}$ & $\begin{array}{c}\mathrm{RD} \\
\text { estimate }\end{array}$ & $\begin{array}{l}\text { t-stat on } \\
\text { RD } \\
\text { estimate }\end{array}$ \\
\hline \multicolumn{8}{|l|}{ Political characteristics } \\
\hline Mun. taxes per capita (2005) & 59.84 & 56.75 & $(0.23)$ & 40.96 & $(0.86)$ & 10.80 & $(0.42)$ \\
\hline Turnout & 0.61 & 0.59 & $(0.99)$ & 0.05 & $(0.77)$ & 0.02 & $(0.42)$ \\
\hline PAN incumbent & 0.27 & 0.32 & $(-0.61)$ & -0.05 & $(-0.22)$ & 0.14 & $(1.52)$ \\
\hline PRD incumbent & 0.17 & 0.13 & $(0.63)$ & -0.02 & $(-0.12)$ & -0.16 & $(-1.42)$ \\
\hline$\%$ alternations (1976-2006) & 0.31 & 0.31 & $(-0.01)$ & 0.06 & $(0.70)$ & 0.01 & $(0.25)$ \\
\hline PRI never lost (1976-2006) & 0.07 & 0.07 & $(-0.04)$ & -0.21 & $(-1.64)$ & -0.15 & $(-1.61)$ \\
\hline \multicolumn{8}{|l|}{ Demographic characteristics } \\
\hline Population (2005) & 6.03 & 5.10 & $(0.35)$ & 5.08 & $(0.60)$ & -1.37 & $(-0.62)$ \\
\hline Population density (2005) & 220.23 & 191.05 & $(0.42)$ & -374.00 & $(-1.42)$ & -186.70 & $(-1.19)$ \\
\hline Migrants per capita $(2005)$ & 0.02 & 0.02 & $(-0.69)$ & 0.00 & $(-0.06)$ & 0.00 & $(-0.77)$ \\
\hline \multicolumn{8}{|l|}{ Economic characteristics } \\
\hline Income per capita (2005) & 4.29 & 4.48 & $(-0.53)$ & -0.69 & $(-0.56)$ & 0.10 & $(0.15)$ \\
\hline Malnutrition (2005) & 32.76 & 31.20 & $(0.53)$ & 3.90 & $(0.50)$ & -5.23 & $(-0.89)$ \\
\hline Mean years schooling (2005) & 6.26 & 6.19 & $(0.32)$ & -0.55 & $(-0.77)$ & -0.10 & $(-0.22)$ \\
\hline Infant mortality $(2005)$ & 22.54 & 22.26 & $(0.22)$ & 0.80 & $(0.22)$ & 0.39 & $(0.17)$ \\
\hline $\mathrm{HH}$ w/o access to sewage (2005) & 8.51 & 8.44 & $(0.05)$ & 0.80 & $(0.26)$ & -1.53 & $(-0.52)$ \\
\hline $\mathrm{HH}$ w/o access to water (2005) & 16.14 & 18.22 & $(-0.62)$ & -8.35 & $(-1.06)$ & -6.45 & $(-0.97)$ \\
\hline Marginality index (2005) & -0.15 & -0.12 & $(-0.23)$ & -0.05 & $(-0.13)$ & -0.23 & $(-0.73)$ \\
\hline \multicolumn{8}{|l|}{ Road network characteristics } \\
\hline Detour length $(\mathrm{km})$ & 26.15 & 22.48 & $(0.19)$ & -53.47 & $(-1.29)$ & -14.63 & $(-0.90)$ \\
\hline Road density & 0.15 & 0.13 & $(0.98)$ & -0.06 & $(-1.08)$ & -0.04 & $(-0.86)$ \\
\hline Distance U.S. $(\mathrm{km})$ & 708.27 & 735.49 & $(-0.55)$ & -126.82 & $(-0.86)$ & -135.29 & $(-0.92)$ \\
\hline \multicolumn{8}{|l|}{ Geographic characteristics } \\
\hline Elevation $(\mathrm{m})$ & 1403.42 & 1367.95 & $(0.26)$ & 547.41 & $(1.29)$ & 487.19 & $(1.24)$ \\
\hline Slope (degrees) & 3.62 & 3.19 & $(1.02)$ & 0.26 & $(0.22)$ & -0.17 & $(-0.18)$ \\
\hline Surface area $\left(\mathrm{km}^{2}\right)$ & 1787.36 & 725.37 & $(1.36)$ & 1808.90 & $(1.61)$ & 544.10 & $(0.65)$ \\
\hline Average min. temperature, $\mathrm{C}$ & 7.17 & 7.59 & $(-0.46)$ & -4.56 & $(-1.60)$ & -4.04 & $(-1.51)$ \\
\hline Average max. temperature, $\mathrm{C}$ & 22.54 & 22.90 & $(-0.53)$ & -3.44 & $(-1.58)$ & $-3.24^{*}$ & $(-1.66)$ \\
\hline Average precipitation, $\mathrm{cm}$ & 1164.40 & 1084.63 & $(0.65)$ & -93.64 & $(-0.32)$ & -90.74 & $(-0.32)$ \\
\hline Observations & 70 & 82 & & 152 & & 152 & \\
\hline
\end{tabular}

Notes: Data on population, population density, mean years of schooling, and migrants per capita are from II Conteo de Poblacion y Vivienda, INEGI (National Institute of Statistics and Geography, 2005). Data on municipal tax collection are from Sistema de Cuentas Municipales, INEGI. Data on household access to sewage and water are from CONAPO (National Population Council) (2005). Data on malnutrition are from CONEVAL (National Council for Evaluating Social Development Policy), Indice de Reazgo Social (2005). Data on infant mortality are from PNUD Mexico (UN Development Program, 2005). The marginality index is from CONAPO (2005). Data on distance to the U.S. and other road network characteristics are from the author's own calculations. Electoral data are from Mexico Electoral-Banamex and electoral results published by the Electoral Tribunals of each state. For 11 states, data on the total number of eligible voters, required to calculate turnout, are not reported. The geographic characteristics are from Acemoglu and Dell (2009). Columns (1) through (5) examine these variables for municipalities with close elections. Column (6) and (7) examine these characteristics for municipalities that border a municipality with a close election. Column (3) reports the t-statistic on the difference in means between municipalities where the PAN barely won and where they barely lost. Columns (4) and (6) report the coefficient on PAN win from a standard RD specification where the respective characteristic is used as the dependent variable, and columns (5) and (7) report the respective t-statistic. ${ }^{*}$ significant at $10 \%,{ }^{* *}$ significant at $5 \%,{ }^{* * *}$ significant at $1 \%$. 
Table 2: Close PAN Elections and Homicides (2007-2008 elections)

\begin{tabular}{|c|c|c|c|c|c|c|c|c|c|c|c|c|}
\hline & \multicolumn{6}{|c|}{ Homicide Probability } & \multicolumn{6}{|c|}{ Homicide Rate } \\
\hline & \multicolumn{3}{|c|}{ Quadratic RD Polynomial } & \multicolumn{3}{|c|}{ Linear RD Polynomial } & \multicolumn{3}{|c|}{ Quadratic RD Polynomial } & \multicolumn{3}{|c|}{ Linear RD Polynomial } \\
\hline & $\begin{array}{l}\text { Post } \\
\text { inaug. }\end{array}$ & $\begin{array}{l}\text { Lame } \\
\text { duck }\end{array}$ & $\begin{array}{c}\text { Pre } \\
\text { election }\end{array}$ & $\begin{array}{l}\text { Post } \\
\text { inaug. }\end{array}$ & $\begin{array}{l}\text { Lame } \\
\text { duck }\end{array}$ & $\begin{array}{c}\text { Pre } \\
\text { election }\end{array}$ & $\begin{array}{l}\text { Post } \\
\text { inaug. }\end{array}$ & $\begin{array}{l}\text { Lame } \\
\text { duck }\end{array}$ & $\begin{array}{c}\text { Pre } \\
\text { election }\end{array}$ & $\begin{array}{l}\text { Post } \\
\text { inaug. }\end{array}$ & $\begin{array}{l}\text { Lame } \\
\text { duck }\end{array}$ & $\begin{array}{c}\text { Pre } \\
\text { election }\end{array}$ \\
\hline & (1) & $(2)$ & $(3)$ & $(4)$ & $(5)$ & $(6)$ & $(7)$ & $(8)$ & $(9)$ & $(10)$ & $(11)$ & $(12)$ \\
\hline \multicolumn{13}{|c|}{ Panel A: Drug trade-related homicides } \\
\hline PAN win & $\begin{array}{c}0.068 \\
(0.139)\end{array}$ & $\begin{array}{c}0.144 \\
(0.127)\end{array}$ & $\begin{array}{c}-0.004 \\
(0.124)\end{array}$ & $\begin{array}{c}0.053 \\
(0.090)\end{array}$ & $\begin{array}{c}0.051 \\
(0.082)\end{array}$ & $\begin{array}{c}-0.003 \\
(0.076)\end{array}$ & $\begin{array}{c}41.658^{* * *} \\
(8.194)\end{array}$ & $\begin{array}{c}3.875 \\
(3.888)\end{array}$ & $\begin{array}{c}-4.537 \\
(4.206)\end{array}$ & $\begin{array}{c}32.981^{* * *} \\
(9.346)\end{array}$ & $\begin{array}{c}4.967 \\
(4.122)\end{array}$ & $\begin{array}{l}-2.038 \\
(3.776)\end{array}$ \\
\hline$R^{2}$ & 0.03 & 0.04 & 0.07 & 0.01 & 0.01 & 0.04 & 0.40 & 0.04 & 0.13 & 0.33 & 0.04 & 0.11 \\
\hline Obs. & 152 & 152 & 152 & 152 & 152 & 152 & 152 & 152 & 152 & 152 & 152 & 152 \\
\hline \multicolumn{13}{|c|}{ Panel B: All homicides } \\
\hline PAN win & $\begin{array}{c}0.050 \\
(0.144)\end{array}$ & $\begin{array}{c}-0.042 \\
(0.153)\end{array}$ & $\begin{array}{c}-0.018 \\
(0.133)\end{array}$ & $\begin{array}{c}0.037 \\
(0.101)\end{array}$ & $\begin{array}{c}0.031 \\
(0.101)\end{array}$ & $\begin{array}{c}0.020 \\
(0.089)\end{array}$ & $\begin{array}{c}68.550^{* * *} \\
(10.105)\end{array}$ & $\begin{array}{c}4.442 \\
(3.142)\end{array}$ & $\begin{array}{l}-1.951 \\
(5.571)\end{array}$ & $\begin{array}{c}56.630^{* * *} \\
(12.768)\end{array}$ & $\begin{array}{c}2.457 \\
(2.922)\end{array}$ & $\begin{array}{c}3.088 \\
(4.361)\end{array}$ \\
\hline$R^{2}$ & 0.04 & 0.03 & 0.05 & 0.01 & 0.01 & 0.01 & 0.45 & 0.03 & 0.07 & 0.40 & 0.03 & 0.04 \\
\hline Obs. & 152 & 152 & 152 & 152 & 152 & 152 & 152 & 152 & 152 & 152 & 152 & 152 \\
\hline
\end{tabular}

Notes: Panel A examines drug-related homicides, and Panel B examines all homicides. In columns (1) and (4) the dependent variable is the average monthly homicide probability during the mayor's term, and in columns (7) and (10) it is the average homicide rate. Columns (2), (5), (8), and (11) similarly examine homicides during the lame duck period, and columns (3), (6), (9), and (12) examine homicides during the pre-election period. PAN win is an indicator equal to one if a PAN candidate won the election, and the sample includes elections in 2007-2008 where the PAN was first or second by a 5 percentage point or less vote spread margin. Columns (1) through (3) and (7) through (9) include a quadratic RD polynomial estimated separately on either side of the PAN win-loss threshold. Columns (4) through (6) and (10) through (12) include a linear RD polynomial estimated separately on either side of the threshold. $*$ significant at $10 \%, * *$ significant at $5 \%, * * *$ significant at $1 \%$. 
Table 3: Close PAN Elections and Homicides (2007-2010 elections)

\begin{tabular}{|c|c|c|c|c|c|c|c|c|c|c|c|c|}
\hline & \multicolumn{6}{|c|}{ Homicide Probability } & \multicolumn{6}{|c|}{ Homicide Rate } \\
\hline & \multicolumn{3}{|c|}{ Quadratic RD Polynomial } & \multicolumn{3}{|c|}{ Linear RD Polynomial } & \multicolumn{3}{|c|}{ Quadratic RD Polynomial } & \multicolumn{3}{|c|}{ Linear RD Polynomial } \\
\hline & $\begin{array}{l}\text { Post } \\
\text { inaug. }\end{array}$ & $\begin{array}{l}\text { Lame } \\
\text { duck }\end{array}$ & $\begin{array}{c}\text { Pre } \\
\text { election }\end{array}$ & $\begin{array}{l}\text { Post } \\
\text { inaug. }\end{array}$ & $\begin{array}{l}\text { Lame } \\
\text { duck }\end{array}$ & $\begin{array}{c}\text { Pre } \\
\text { election }\end{array}$ & $\begin{array}{l}\text { Post } \\
\text { inaug. }\end{array}$ & $\begin{array}{l}\text { Lame } \\
\text { duck }\end{array}$ & $\begin{array}{c}\text { Pre } \\
\text { election }\end{array}$ & $\begin{array}{l}\text { Post } \\
\text { inaug. }\end{array}$ & $\begin{array}{l}\text { Lame } \\
\text { duck }\end{array}$ & $\begin{array}{c}\text { Pre } \\
\text { election }\end{array}$ \\
\hline & (1) & $(2)$ & $(3)$ & $(4)$ & $(5)$ & $(6)$ & $(7)$ & $(8)$ & $(9)$ & $(10)$ & $(11)$ & $(12)$ \\
\hline \multicolumn{13}{|c|}{ Panel A: Drug trade-related homicides } \\
\hline PAN win & $\begin{array}{c}0.004 \\
(0.085)\end{array}$ & $\begin{array}{c}0.032 \\
(0.085)\end{array}$ & $\begin{array}{l}-0.036 \\
(0.079)\end{array}$ & $\begin{array}{c}0.042 \\
(0.054)\end{array}$ & $\begin{array}{c}0.030 \\
(0.054)\end{array}$ & $\begin{array}{c}0.027 \\
(0.050)\end{array}$ & $\begin{array}{c}17.635^{* * *} \\
(6.489)\end{array}$ & $\begin{array}{c}1.132 \\
(4.895)\end{array}$ & $\begin{array}{l}-4.574 \\
(4.774)\end{array}$ & $\begin{array}{c}26.735^{* * *} \\
(8.560)\end{array}$ & $\begin{array}{c}6.331 \\
(5.212)\end{array}$ & $\begin{array}{c}3.830 \\
(4.688)\end{array}$ \\
\hline$R^{2}$ & 0.04 & 0.01 & 0.02 & 0.02 & 0.01 & 0.01 & 0.13 & 0.01 & 0.02 & 0.10 & 0.01 & 0.01 \\
\hline Clusters & 307 & 307 & 307 & 307 & 307 & 307 & 307 & 307 & 307 & 307 & 307 & 307 \\
\hline Obs. & 310 & 310 & 310 & 310 & 310 & 310 & 310 & 310 & 310 & 310 & 310 & 310 \\
\hline \multicolumn{13}{|c|}{ Panel B: All homicides } \\
\hline PAN win & $\begin{array}{c}-0.014 \\
(0.097)\end{array}$ & $\begin{array}{l}-0.108 \\
(0.106)\end{array}$ & $\begin{array}{l}-0.016 \\
(0.085)\end{array}$ & $\begin{array}{c}0.053 \\
(0.064)\end{array}$ & $\begin{array}{c}0.001 \\
(0.071)\end{array}$ & $\begin{array}{c}0.039 \\
(0.054)\end{array}$ & $\begin{array}{c}35.970 * * * \\
(9.351)\end{array}$ & $\begin{array}{l}-2.048 \\
(5.665)\end{array}$ & $\begin{array}{c}-0.669 \\
(4.767)\end{array}$ & $\begin{array}{c}44.820^{* * *} \\
(12.289)\end{array}$ & $\begin{array}{c}6.622 \\
(6.665)\end{array}$ & $\begin{array}{c}4.740 \\
(3.498)\end{array}$ \\
\hline$R^{2}$ & 0.03 & 0.02 & 0.04 & 0.02 & 0.01 & 0.03 & 0.27 & 0.02 & 0.07 & 0.24 & 0.01 & 0.03 \\
\hline Clusters & 307 & 307 & 307 & 307 & 307 & 307 & 307 & 307 & 307 & 307 & 307 & 307 \\
\hline Obs. & 310 & 310 & 310 & 310 & 310 & 310 & 310 & 310 & 310 & 310 & 310 & 310 \\
\hline
\end{tabular}

Notes: Panel A examines drug-related homicides, and Panel B examines all homicides. In columns (1) and (4) the dependent variable is the average monthly homicide probability during the one year following the mayor's inauguration, and in columns (7) and (10) it is the average homicide rate. Columns (2), (5), (8), and (11) similarly examine homicides during the lame duck period, and columns (3), (6), (9), and (12) examine homicides during the pre-election period. PAN win is an indicator equal to one if a PAN candidate won the election, and the sample includes elections in 2007-2010 where the PAN was first or second by a 5 percentage point or less vote spread margin. Columns (1) through (3) and (7) through (9) include a quadratic RD polynomial estimated separately on either side of the PAN win-loss threshold. Columns (4) through (6) and (10) through (12) include a linear RD polynomial estimated separately on either side of the threshold. Standard errors are clustered by municipality. ${ }^{*}$ significant at $10 \%,{ }^{* *}$ significant at $5 \%,{ }^{* *}$ significant at $1 \%$. 
Table 4: Heterogeneity

\begin{tabular}{|c|c|c|c|c|c|c|c|c|}
\hline & \multicolumn{8}{|c|}{ Dependent variable: drug-related homicide rate } \\
\hline & \multicolumn{4}{|c|}{ 2007-2008 elections } & \multicolumn{4}{|c|}{ 2007-2010 elections } \\
\hline & $(1)$ & $(2)$ & $(3)$ & $(4)$ & $(5)$ & (6) & $(7)$ & $(8)$ \\
\hline PAN win & $\begin{array}{c}32.981^{* * * *} \\
(9.346)\end{array}$ & $\begin{array}{c}37.699^{* * *} \\
(9.000)\end{array}$ & $\begin{array}{c}37.333^{* * *} \\
(9.752)\end{array}$ & $\begin{array}{l}-2.344 \\
(4.020)\end{array}$ & $\begin{array}{c}26.735^{* * *} \\
(8.560)\end{array}$ & $\begin{array}{c}32.594^{* * *} \\
(10.261)\end{array}$ & $\begin{array}{c}30.333^{* * *} \\
(8.725)\end{array}$ & $\begin{array}{l}-0.781 \\
(8.164)\end{array}$ \\
\hline $\begin{array}{l}\text { PAN win } \mathrm{x} \\
\text { far from U.S. }\end{array}$ & & $\begin{array}{c}-49.364^{* * *} \\
(12.674)\end{array}$ & & & & $\begin{array}{c}-34.487^{* * *} \\
(11.231)\end{array}$ & & \\
\hline $\begin{array}{l}\text { PAN win } \mathrm{x} \\
\text { low violence }\end{array}$ & & & $\begin{array}{c}-51.267^{* * *} \\
(11.524)\end{array}$ & & & & $\begin{array}{c}-38.262^{* * *} \\
(9.709)\end{array}$ & \\
\hline $\begin{array}{l}\text { PAN win } \mathrm{x} \\
\text { local gang }\end{array}$ & & & & $\begin{array}{c}0.331 \\
(14.867)\end{array}$ & & & & $\begin{array}{c}1.000 \\
(9.978)\end{array}$ \\
\hline $\begin{array}{l}\text { PAN win } \mathrm{x} \\
\text { rival }\end{array}$ & & & & $\begin{array}{c}33.747^{* * *} \\
(10.827)\end{array}$ & & & & $\begin{array}{c}33.680^{* *} \\
(16.747)\end{array}$ \\
\hline $\begin{array}{l}\text { PAN win } \mathrm{x} \\
\text { ally }\end{array}$ & & & & $\begin{array}{c}11.522 \\
(10.992)\end{array}$ & & & & $\begin{array}{c}4.900 \\
(9.405)\end{array}$ \\
\hline R-squared & 0.326 & 0.433 & 0.443 & 0.504 & 0.102 & 0.201 & 0.216 & 0.220 \\
\hline Clusters & 152 & 152 & 152 & 152 & 307 & 307 & 307 & 307 \\
\hline Observations & 152 & 152 & 152 & 152 & 310 & 310 & 310 & 310 \\
\hline $\begin{array}{l}\text { PAN win effect } \\
\text { (far from US) }\end{array}$ & & $\begin{array}{l}-11.670 \\
(8.924)\end{array}$ & & & & $\begin{array}{l}-1.892 \\
(4.566)\end{array}$ & & \\
\hline $\begin{array}{l}\text { PAN win effect } \\
\text { (low violence) }\end{array}$ & & & $\begin{array}{c}-13.930^{* *} \\
(6.140)\end{array}$ & & & & $\begin{array}{l}-7.928^{*} \\
(4.259)\end{array}$ & \\
\hline $\begin{array}{l}\text { PAN win effect } \\
\text { (local gang) }\end{array}$ & & & & $\begin{array}{c}-2.013 \\
(14.310)\end{array}$ & & & & $\begin{array}{c}0.219 \\
(5.736)\end{array}$ \\
\hline $\begin{array}{l}\text { PAN win effect } \\
\text { (rival) }\end{array}$ & & & & $\begin{array}{c}31.400^{* * *} \\
(10.050)\end{array}$ & & & & $\begin{array}{c}32.900^{* *} \\
(14.620)\end{array}$ \\
\hline $\begin{array}{l}\text { PAN win effect } \\
\text { (ally) }\end{array}$ & & & & $\begin{array}{c}9.178 \\
(10.230)\end{array}$ & & & & $\begin{array}{c}4.119 \\
(4.669)\end{array}$ \\
\hline
\end{tabular}

Notes: PAN win is an indicator equal to one if a PAN candidate won the election, far from U.S. is an indicator equal to 1 if the municipality is above median distance from the U.S., low violence is an indicator equal to 1 if the municipality had a below median homicide rate during 2004-2006, local gang is an indicator equal to one if the municipality contains only a local gang, rival is an indicator equal to one if it contains a major DTO and borders territory controlled by a rival DTO, and ally is an indicator equal to one if it contains a major DTO and does not border territory controlled by a rival DTO. All columns limit the sample to municipalities where a PAN candidate was the winner or runner-up by less than a five percentage point vote spread margin and include a linear RD polynomial estimated separately on either side of the PAN win-loss threshold. In addition to the interactions, main effects are also included. Standard errors, clustered by municipality, are in parentheses. ${ }^{*}$ significant at $10 \%,{ }^{* *}$ significant at $5 \%,{ }^{* * *}$ significant at $1 \%$. 
Table 5: Local Politics and Violence

\begin{tabular}{|c|c|c|c|c|c|c|c|c|c|c|c|c|}
\hline \multicolumn{13}{|c|}{ Dependent variable: drug-related homicide rate } \\
\hline & \multicolumn{6}{|c|}{ 2007-2008 elections } & \multicolumn{6}{|c|}{ 2007-2010 elections } \\
\hline & (1) & $(2)$ & $(3)$ & $(4)$ & $(5)$ & $(6)$ & $(7)$ & $(8)$ & $(9)$ & $(10)$ & $(11)$ & $(12)$ \\
\hline PAN win & $\begin{array}{c}32.981^{* * *} \\
(9.346)\end{array}$ & $\begin{array}{c}30.134^{* * *} \\
(8.082)\end{array}$ & & & & $\begin{array}{c}34.038^{* * *} \\
(11.173)\end{array}$ & $\begin{array}{c}26.735^{* * *} \\
(8.560)\end{array}$ & $\begin{array}{c}33.336^{* * *} \\
(9.801)\end{array}$ & & & & $\begin{array}{c}24.123^{* * *} \\
(6.531)\end{array}$ \\
\hline $\begin{array}{l}\text { PAN win } \mathrm{x} \\
\text { PAN incumb. }\end{array}$ & & $\begin{array}{c}-32.965^{* * *} \\
(9.704)\end{array}$ & & & & & & $\begin{array}{c}-32.812^{* * *} \\
(10.999)\end{array}$ & & & & \\
\hline Alter (PAN) & & & $\begin{array}{c}8.147 \\
(6.313)\end{array}$ & & & & & & $\begin{array}{c}2.996 \\
(6.041)\end{array}$ & & & \\
\hline PRI win & & & & $\begin{array}{c}11.523 \\
(10.550)\end{array}$ & & & & & & $\begin{array}{c}1.693 \\
(13.092)\end{array}$ & & \\
\hline Alter (PRI/PRD) & & & & & $\begin{array}{c}4.419 \\
(3.728)\end{array}$ & & & & & & $\begin{array}{l}-2.795 \\
(6.078)\end{array}$ & \\
\hline $\begin{array}{l}\text { PAN win } \mathrm{x} \\
\text { PAN gov. }\end{array}$ & & & & & & $\begin{array}{c}3.617 \\
(15.494)\end{array}$ & & & & & & $\begin{array}{c}0.415 \\
(17.342)\end{array}$ \\
\hline Clusters & 152 & 152 & 152 & 142 & 142 & 152 & 307 & 307 & 307 & 181 & 181 & 307 \\
\hline Observations & 152 & 152 & 152 & 142 & 142 & 152 & 310 & 310 & 310 & 183 & 183 & 310 \\
\hline R-squared & 0.326 & 0.470 & 0.104 & 0.038 & 0.039 & 0.342 & 0.102 & 0.255 & 0.187 & 0.089 & 0.096 & 0.119 \\
\hline $\begin{array}{l}\text { PAN win effect } \\
\text { (PAN incumb.) }\end{array}$ & & $\begin{array}{l}-2.831 \\
(5.370)\end{array}$ & & & & & & $\begin{array}{c}0.524 \\
(4.993)\end{array}$ & & & & \\
\hline $\begin{array}{l}\text { PAN win effect } \\
\text { (PAN gov.) }\end{array}$ & & & & & & $\begin{array}{c}37.660^{* * *} \\
(10.730)\end{array}$ & & & & & & $\begin{array}{c}24.540 \\
(16.070)\end{array}$ \\
\hline $\begin{array}{l}\text { Notes: PAN win is } \\
\text { during the previous } \\
\text { election, and alter is } \\
\text { where a PAN candid } \\
\text { sample to municipal } \\
\text { side of the threshold }\end{array}$ & $\begin{array}{l}\text { an indicator } \\
\text { erm, PAN g } \\
\text { a dummy eq } \\
\text { ate was the } \\
\text { ties with a c } \\
\text { In columns }\end{array}$ & $\begin{array}{l}\text { equal to one } \\
\text { overnor is an } \\
\text { ual one if the } \\
\text { winner or run } \\
\text { lose election } \\
(2),(6),(8) \text {, }\end{array}$ & $\begin{array}{l}\text { a PAN } \\
\text { ndicator } \\
\text { party co } \\
\text { er-up by } \\
\text { etween } \\
\text { and (12) } \\
\text { nificant }\end{array}$ & $\begin{array}{l}\text { ndidate } \\
\text { qual to } 1 \\
\text { olling th } \\
\text { ess than } \\
\text { I and PI }\end{array}$ & $\begin{array}{l}\text { on the e } \\
\text { the sta } \\
\text { mayorsl } \\
\text { five per } \\
\text { candic }\end{array}$ & $\begin{array}{l}\text { ction, PAN } \\
\text { has a PAN } \\
\text { p changed. } \\
\text { ntage point } \\
\text { tes. All coll } \\
\text { included. S }\end{array}$ & $\begin{array}{l}\text { ambent is } \\
\text { jernor, PR } \\
\text { amns (1) - } \\
\text { e spread n } \\
\text { s include a } \\
\text { lard errors }\end{array}$ & $\begin{array}{l}\text { indicator } \mathrm{p} \\
\text { Nin is an in } \\
\text {, (6) - (9), } \\
\text { gin; and cc } \\
\text { near RD pc } \\
\text { lustered by }\end{array}$ & $\begin{array}{l}\text { ial to } 1 \\
\text { cator eq } \\
\text { nd }(12) \\
\text { mns }(4) \\
\text { nomial } \\
\text { anicipa }\end{array}$ & $\begin{array}{l}\text { the PAN } \\
\text { al to } 1 \text { if } \\
\text { mit the } \mathrm{s} \\
(5),(10) \\
\text { timated } \\
y \text {, are in }\end{array}$ & $\begin{array}{l}\text { eld the } 1 \\
\text { e PRI w } \\
\text { aple to } \mathrm{m} \\
\text { nd (11) l } \\
\text { parately } \\
\text { arenthese }\end{array}$ & $\begin{array}{l}\text { layorship } \\
\text { n the } \\
\text { unicipalities } \\
\text { mit the } \\
\text { n either } \\
\text { s. } *\end{array}$ \\
\hline
\end{tabular}


Table 6: The Diversion of Drug Traffic

\begin{tabular}{|c|c|c|c|c|c|c|c|c|c|}
\hline & \multicolumn{6}{|c|}{ Dep. var.: Domestic Illicit Drug Confiscations } & \multicolumn{3}{|c|}{ Cocaine Confiscations } \\
\hline & Dummy & Value & Value & Dummy & Value & Value & Dummy & Value & Value \\
\hline & \multicolumn{3}{|c|}{ Full Sample } & \multicolumn{3}{|c|}{ Limited Sample } & \multicolumn{3}{|c|}{ Full Sample } \\
\hline & $(1)$ & $(2)$ & $(3)$ & $(4)$ & $(5)$ & $(6)$ & $(7)$ & $(8)$ & $(9)$ \\
\hline \multicolumn{10}{|c|}{ Panel A: Shortest Paths } \\
\hline $\begin{array}{l}\text { Predicted } \\
\text { routes dummy }\end{array}$ & $\begin{array}{c}0.016^{* * *} \\
(0.005)\end{array}$ & $\begin{array}{c}0.170^{* * *} \\
(0.050)\end{array}$ & & $\begin{array}{c}0.016^{* *} \\
(0.007)\end{array}$ & $\begin{array}{c}0.169^{* * *} \\
(0.065)\end{array}$ & & $\begin{array}{c}0.004 \\
(0.004)\end{array}$ & $\begin{array}{c}0.028 \\
(0.020)\end{array}$ & \\
\hline $\begin{array}{l}\text { Predicted } \\
\text { routes count }\end{array}$ & & & $\begin{array}{c}0.021^{* * *} \\
(0.008)\end{array}$ & & & $\begin{array}{l}0.015^{*} \\
(0.009)\end{array}$ & & & $\begin{array}{c}0.006 \\
(0.006)\end{array}$ \\
\hline \multicolumn{10}{|c|}{ Panel B: Model with Congestion Costs } \\
\hline $\begin{array}{l}\text { Predicted } \\
\text { routes dummy }\end{array}$ & $\begin{array}{c}0.013^{* *} \\
(0.005)\end{array}$ & $\begin{array}{c}0.149^{* * *} \\
(0.057)\end{array}$ & & $\begin{array}{l}0.011^{*} \\
(0.006)\end{array}$ & $\begin{array}{c}0.129 * * \\
(0.065)\end{array}$ & & $\begin{array}{c}0.002 \\
(0.004)\end{array}$ & $\begin{array}{c}0.009 \\
(0.025)\end{array}$ & \\
\hline $\begin{array}{l}\text { Predicted } \\
\text { routes count }\end{array}$ & & & $\begin{array}{c}0.004 \\
(0.004)\end{array}$ & & & $\begin{array}{c}0.002 \\
(0.004)\end{array}$ & & & $\begin{array}{c}0.001 \\
(0.002)\end{array}$ \\
\hline Municipalities & 1869 & 1869 & 1869 & 1562 & 1562 & 1562 & 1869 & 1869 & 1869 \\
\hline Observations & 69,153 & 69,153 & 69,153 & 57,794 & 57,794 & 57,794 & 69,153 & 69,153 & 69,153 \\
\hline
\end{tabular}

Notes: The dependent variable in columns (1) and (4) is an indicator equal to 1 if domestic illicit drug confiscations are made in a given municipality-month; the dependent variable in columns (2), (3), (5), and (6) is the log value of domestic illicit drug confiscations (or 0 if no confiscations are made); the dependent variable in column (7) is an indicator equal to 1 if cocaine confiscations are made in a given municipality-month; and the dependent variable in columns (8) and (9) is the log value of confiscated cocaine (or 0 if no confiscations are made). Columns (4) through (6) limit the sample to municipalities that do not border a municipality that has experienced a close PAN victory. Panel A predicts trafficking routes using the shortest paths model, and Panel B uses the model with congestion costs. All columns include month x state and municipality fixed effects. Standard errors clustered by municipality and month x state are reported in parentheses. ${ }^{*}$ significant at $10 \%,{ }^{* *}$ significant at $5 \%,{ }^{* * *}$ significant at $1 \%$. 
Table 7: Violence Spillovers

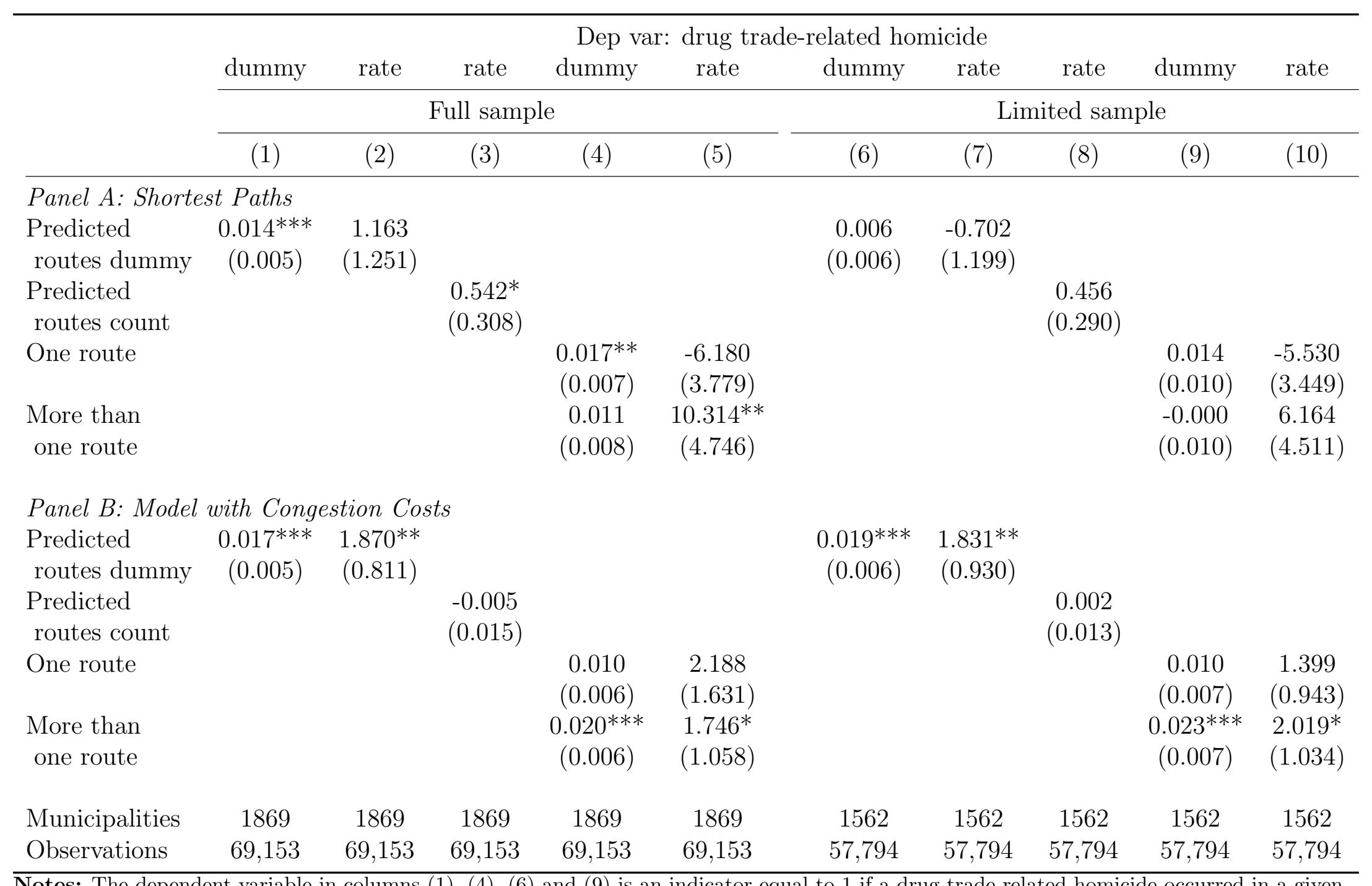

Notes: The dependent variable in columns (1), (4), (6) and (9) is an indicator equal to 1 if a drug trade-related homicide occurred in a given municipality-month, and the dependent variable in columns (2), (3), (5), (7), (8), and (10) is the drug trade-related homicide rate per 100,000 municipal inhabitants. Columns (6) through (10) limit the sample to municipalities that do not border a municipality that has experienced a close PAN victory. All columns include month $\mathrm{x}$ state and municipality fixed effects. Standard errors clustered by municipality and month $\mathrm{x}$ state are reported in parentheses. ${ }^{*}$ significant at $10 \%,{ }^{* *}$ significant at $5 \%,{ }^{* *}$ significant at $1 \%$. 
Figure 1: Illustration of Spillovers Methodology

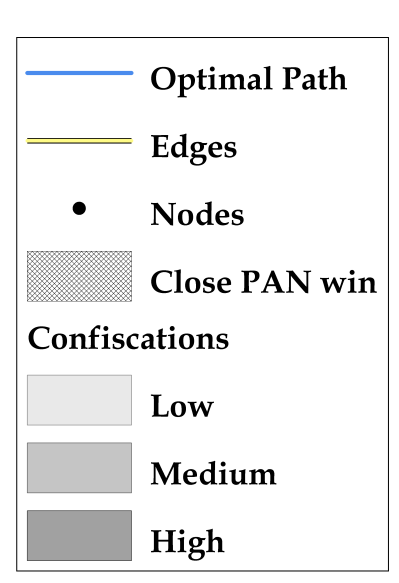

(a) Legend

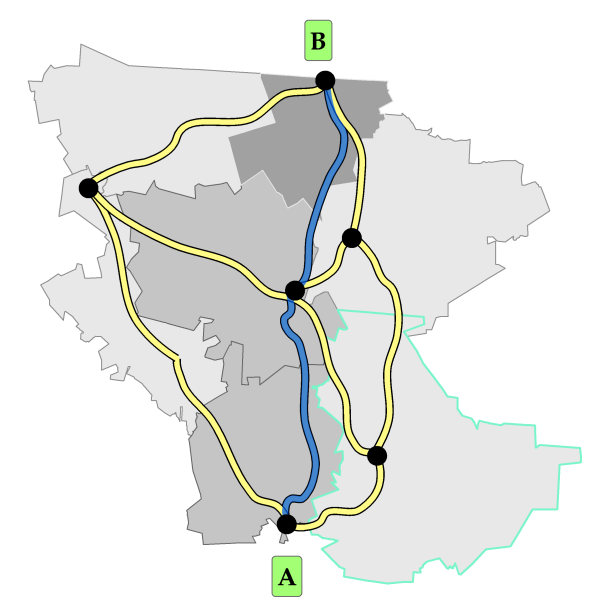

(b) Basic environment

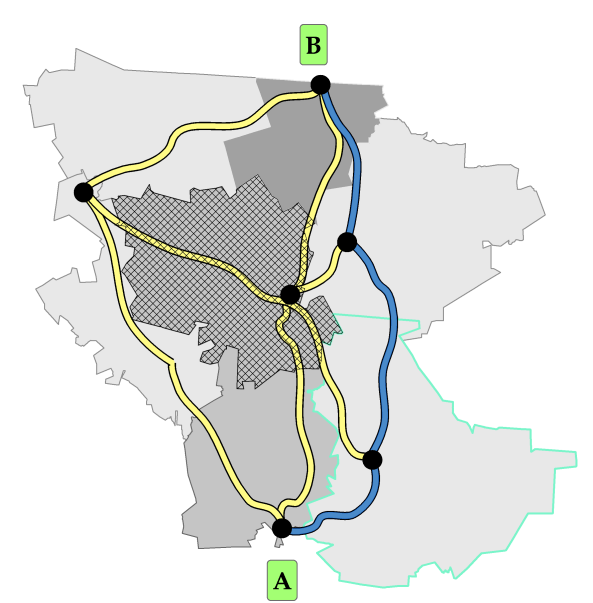

(c) Close PAN victory increases costs; routes change

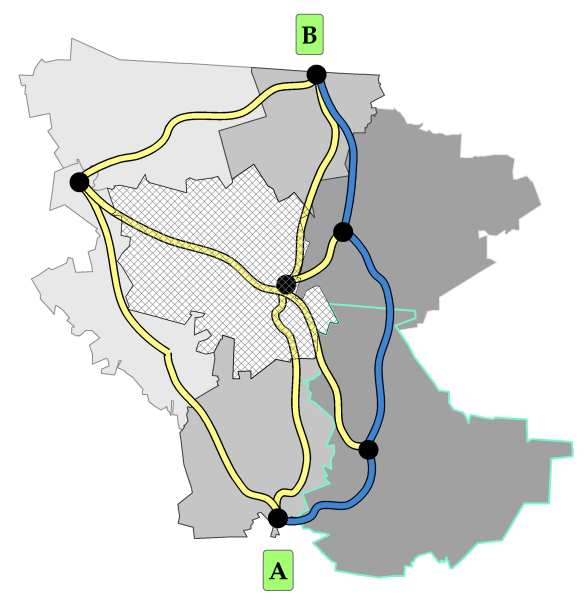

change?

Figure 2: Road Network and Predicted Trafficking Routes

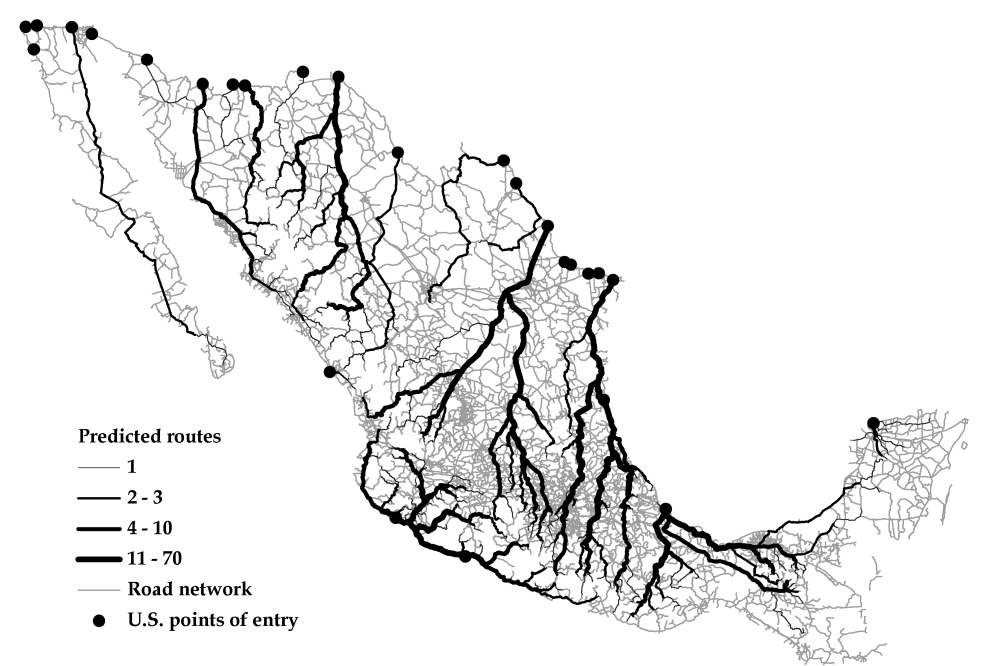

Notes: The least cost routes plotted in this figure are predicted using the network model with congestion costs. 


\section{Figure 3: Drug trade-related homicides RD figures}

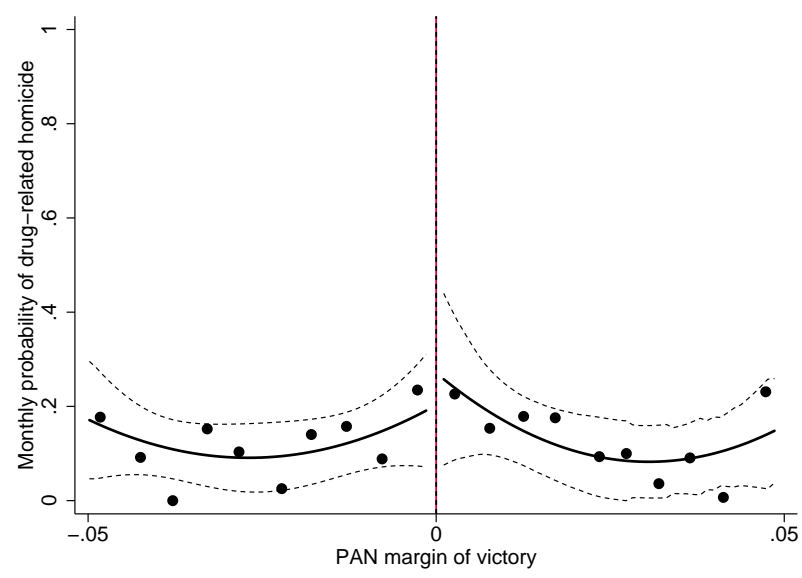

(a) Post-inauguration (extensive margin)

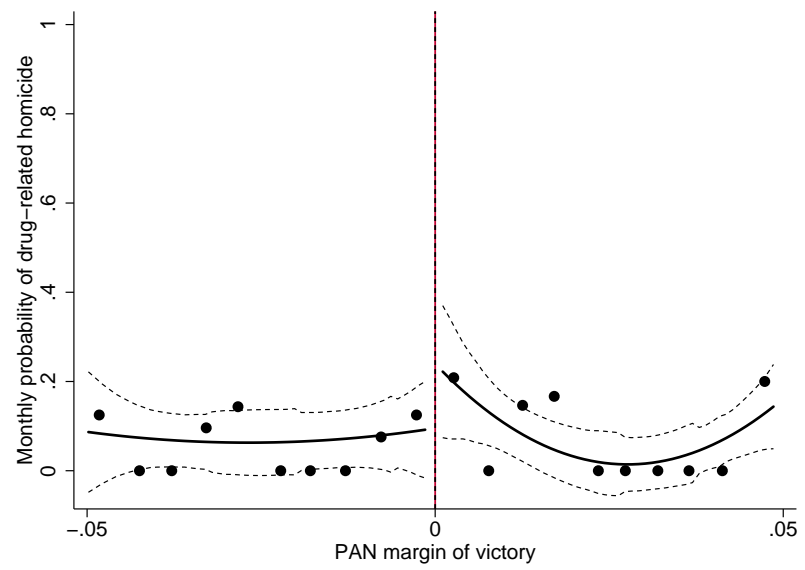

(c) Lame duck (extensive margin)

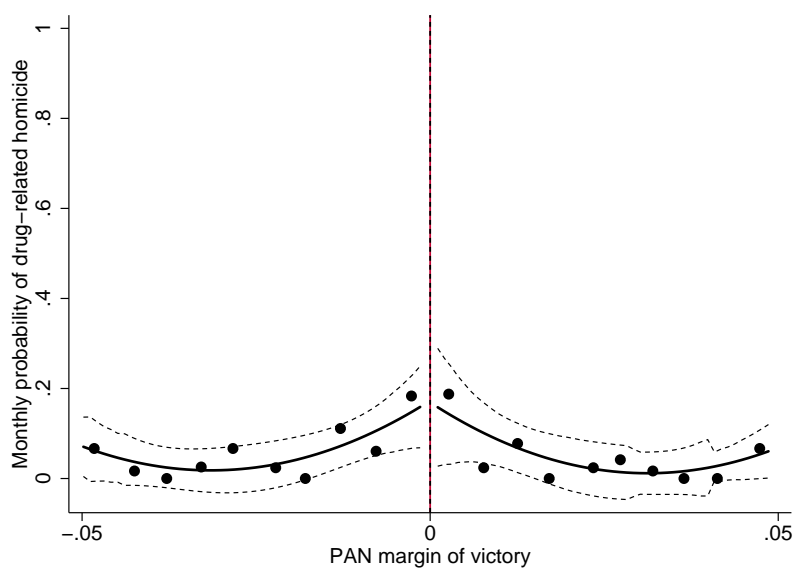

(e) Pre-election (extensive margin)

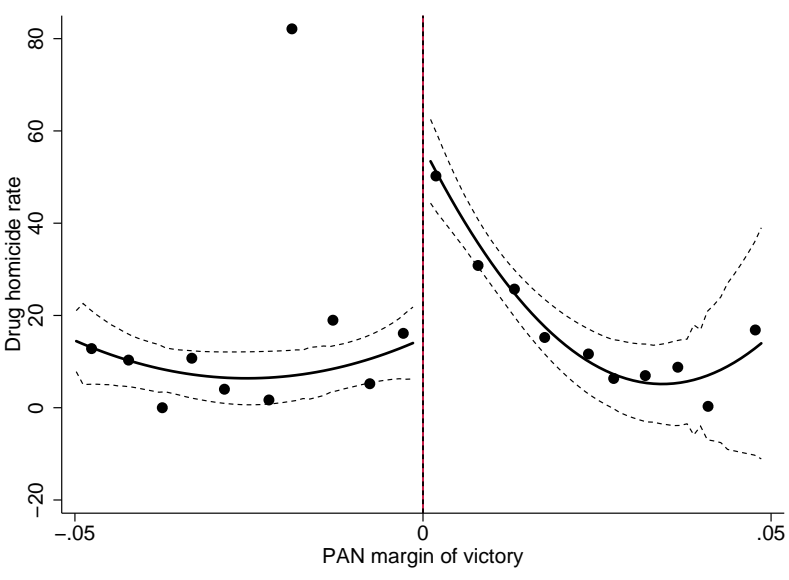

(b) Post-inauguration (homicide rate)

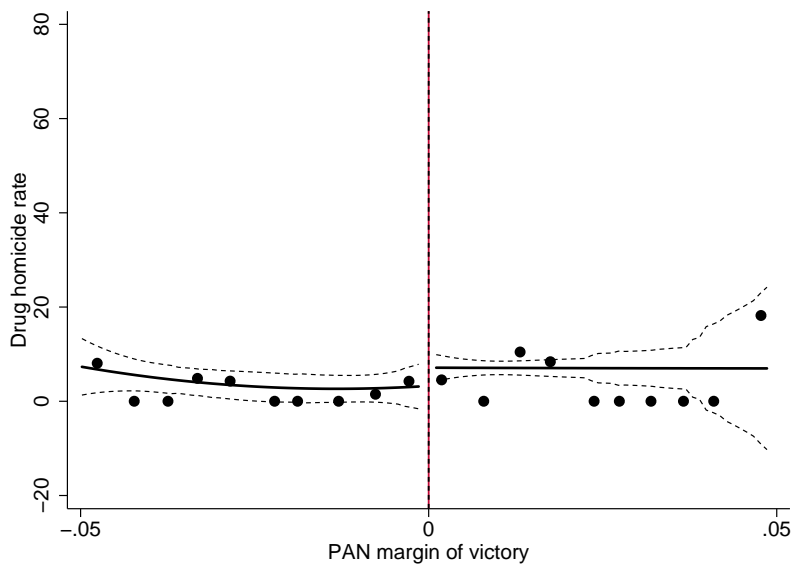

(d) Lame duck (homicide rate)

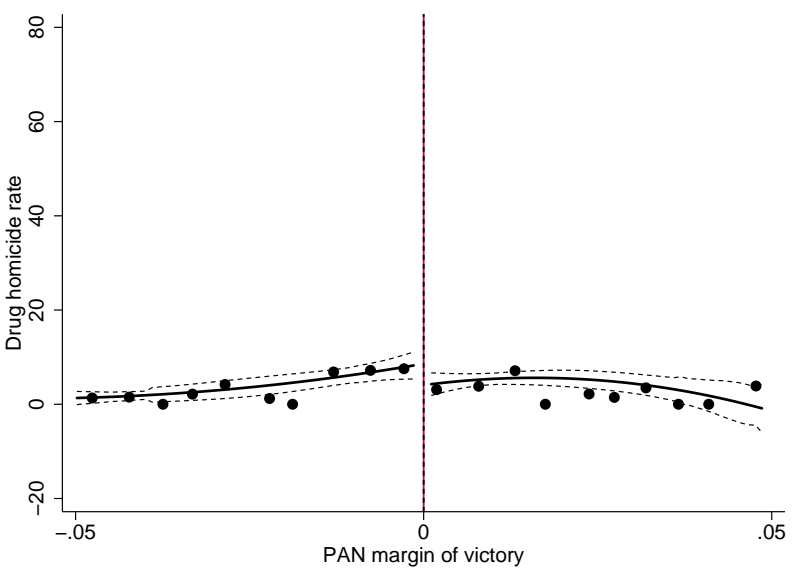

(f) Pre-election (homicide rate)

Notes: This figure plots violence measures against the PAN margin of victory, with a negative margin indicating a PAN loss. Each point represents the average value of the outcome in vote spread bins of width one half of a percentage point. The solid line plots predicted values, with separate quadratic vote spread trends estimated on either side of the PAN win-loss threshold. The dashed lines show $95 \%$ confidence intervals. 


\section{Figure 4: All homicides RD figures}

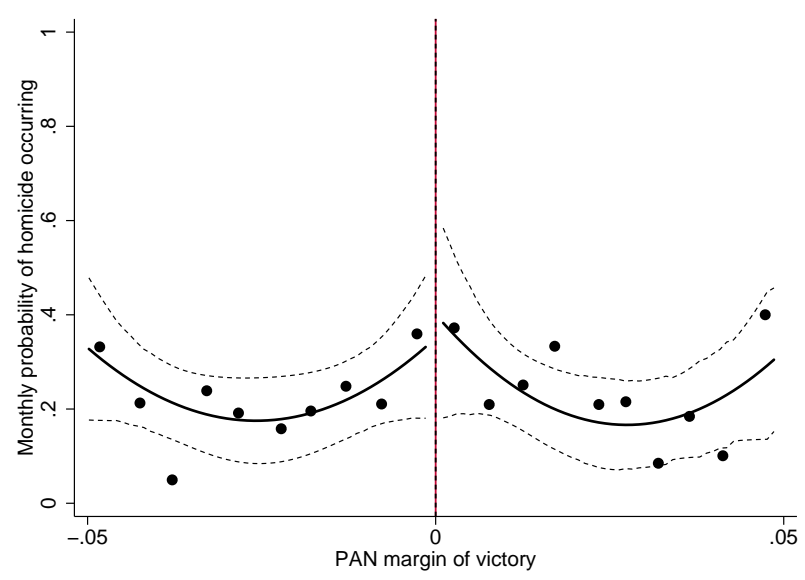

(a) Post-inauguration (extensive margin)

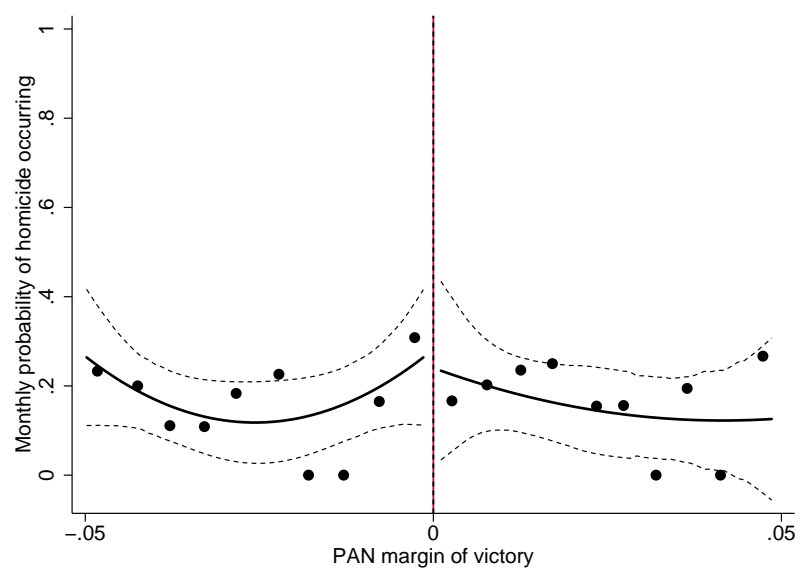

(c) Lame duck (extensive margin)

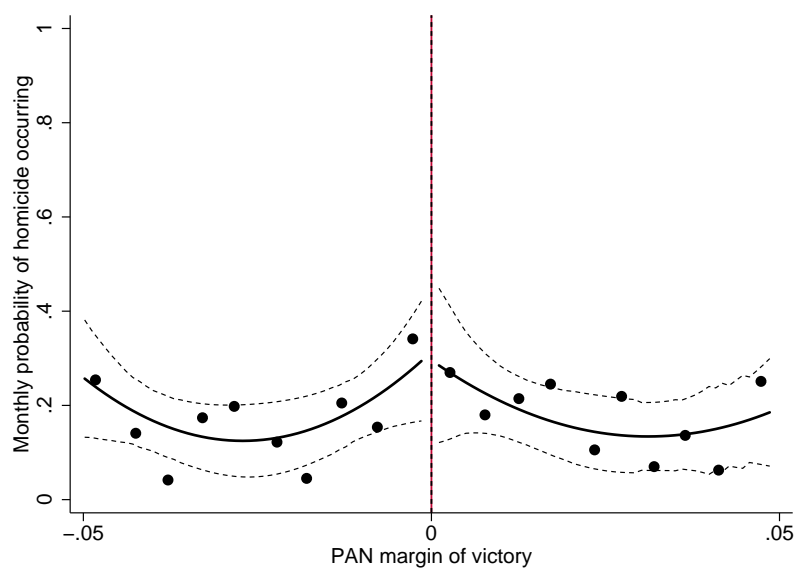

(e) Pre-election (extensive margin)

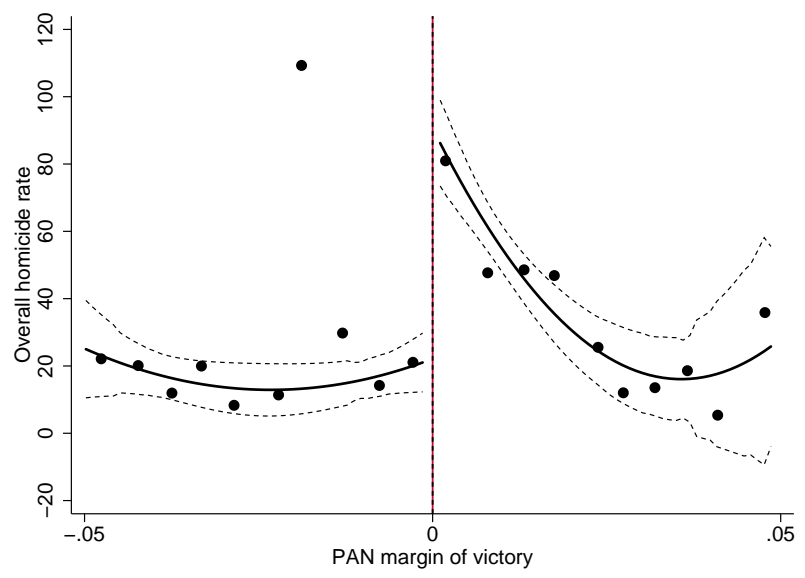

(b) Post-inauguration (homicide rate)

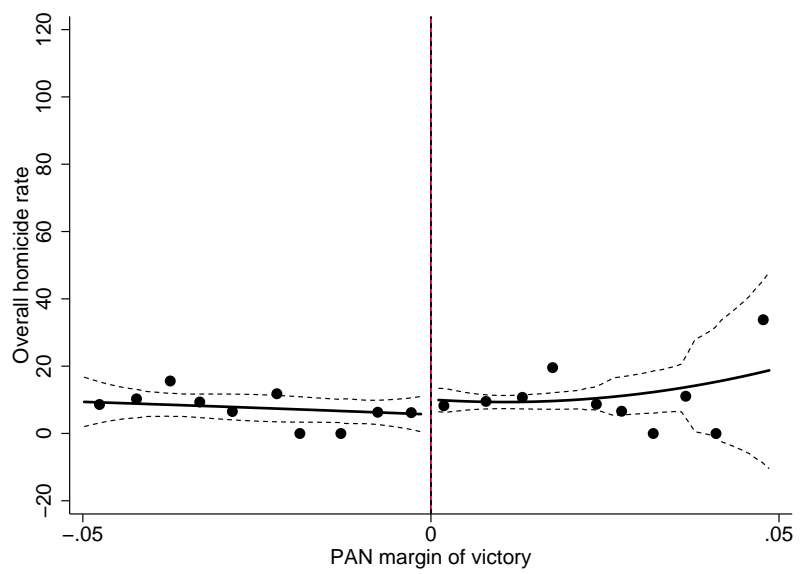

(d) Lame duck (homicide rate)

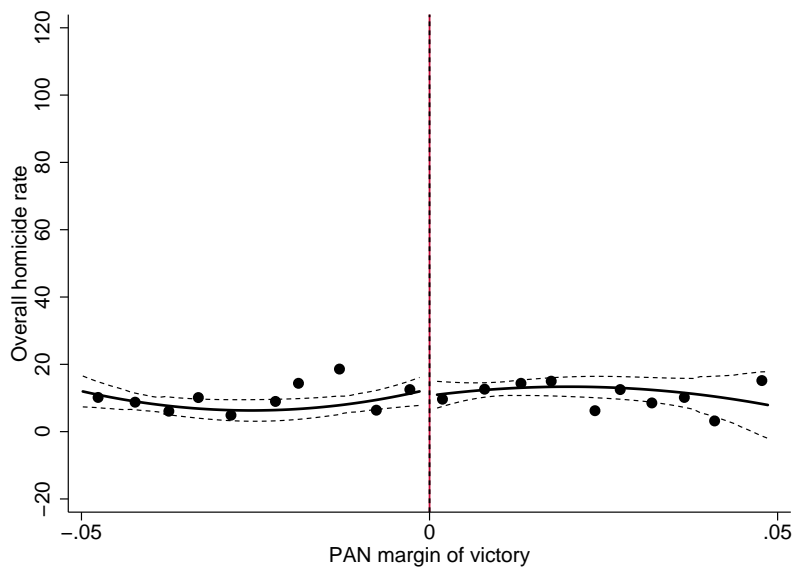

(f) Pre-election (homicide rate)

Notes: This figure plots violence measures against the PAN margin of victory, with a negative margin indicating a PAN loss. Each point represents the average value of the outcome in vote spread bins of width one half of a percentage point. The solid line plots predicted values, with separate quadratic vote spread trends estimated on either side of the PAN win-loss threshold. The dashed lines show $95 \%$ confidence intervals. 


\section{Figure 5: Homicide RD figures}

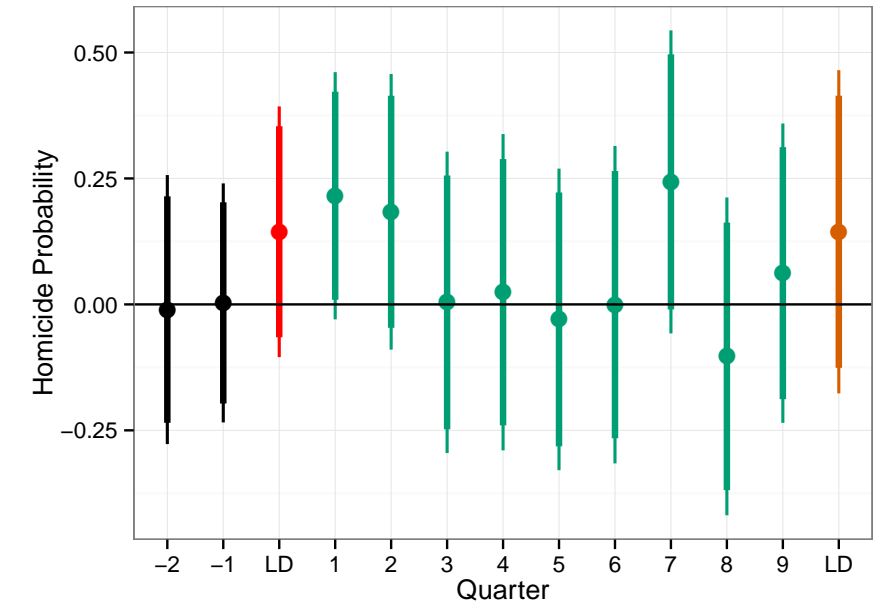

(a) Drug-related homicides (extensive margin)

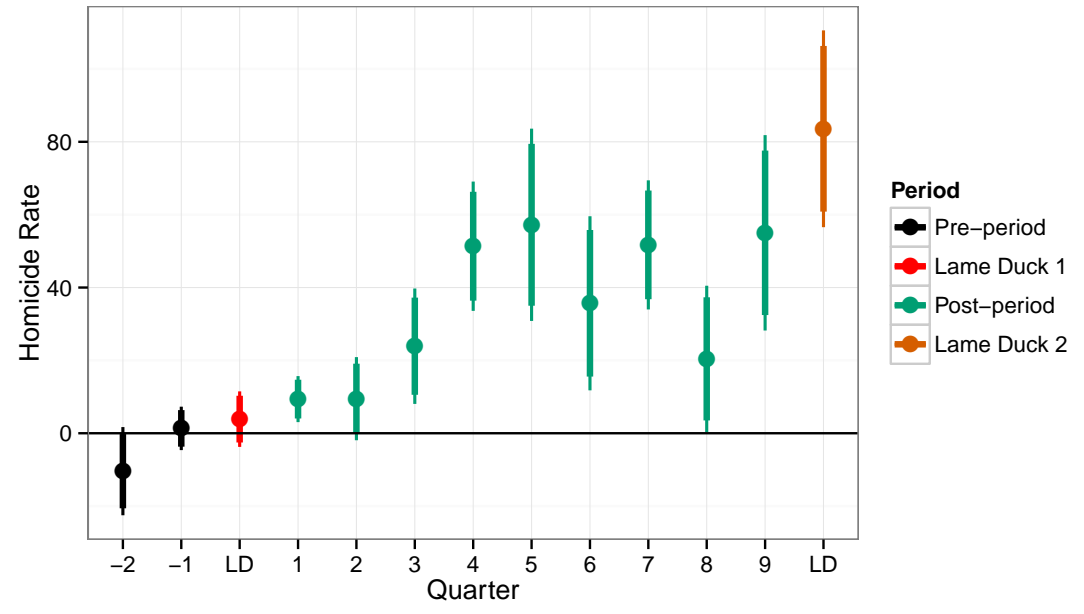

(b) Drug-related homicide rate

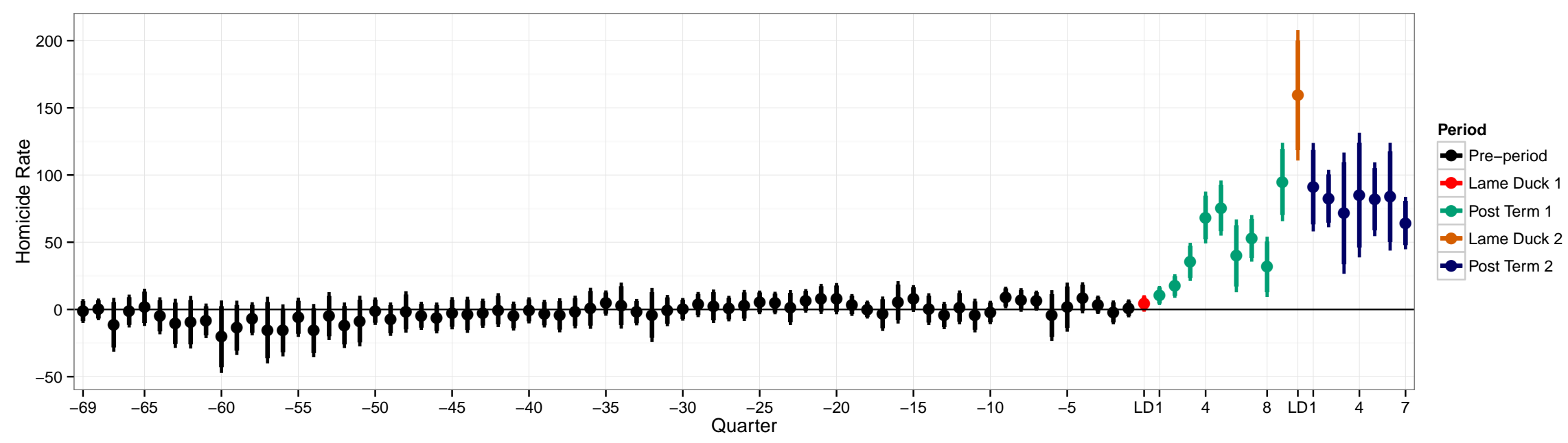

(c) Overall homicide rate

Notes: In Panel A, each point plots a separate RD estimate of the impact of close PAN victories on the average probability that a drug trade-related homicide occurred. In Panel B, each point plots a separate RD estimate of the impact of close PAN victories on the drug-related homicide rate in a given quarter. In Panel C, each point plots a separate RD estimate of the impact of close PAN victories on the overall homicide rate in a given quarter. All regressions include a quadratic RD polynomial, estimated separately on either side of the PAN win-loss threshold. The thin lines plot $95 \%$ confidence intervals, and the thick lines plot $90 \%$ confidence intervals. 